\title{
Maximizing ENSO as a source of western US hydroclimate predictability
}

\author{
Christina M. Patricola ${ }^{1}$ (D ) John P. O'Brien ${ }^{1,2} \cdot$ Mark D. Risser $^{1} \cdot$ Alan M. Rhoades ${ }^{1} \cdot$ Travis A. O'Brien $^{1} \cdot$ Paul A. Ullrich $^{3}$. \\ Dáithí A. Stone $e^{4,5} \cdot$ William D. Collins ${ }^{1,6}$
}

Received: 13 April 2019 / Accepted: 28 September 2019 / Published online: 16 October 2019

(c) The Author(s) 2019

\begin{abstract}
Until recently, the El Niño-Southern Oscillation (ENSO) was considered a reliable source of winter precipitation predictability in the western US, with a historically strong link between extreme El Niño events and extremely wet seasons. However, the 2015-2016 El Niño challenged our understanding of the ENSO-precipitation relationship. California precipitation was near-average during the 2015-2016 El Niño, which was characterized by warm sea surface temperature (SST) anomalies of similar magnitude compared to the extreme 1997-1998 and 1982-1983 El Niño events. We demonstrate that this precipitation response can be explained by El Niño's spatial pattern, rather than internal atmospheric variability. In addition, observations and large-ensembles of regional and global climate model simulations indicate that extremes in seasonal and daily precipitation during strong El Niño events are better explained using the ENSO Longitude Index (ELI), which captures the diversity of ENSO's spatial patterns in a single metric, compared to the traditional Niño3.4 index, which measures SST anomalies in a fixed region and therefore fails to capture ENSO diversity. The physically-based ELI better explains western US precipitation variability because it tracks the zonal shifts in tropical Pacific deep convection that drive teleconnections through the response in the extratropical wave-train, integrated vapor transport, and atmospheric rivers. This research provides evidence that ELI improves the value of ENSO as a predictor of California's seasonal hydroclimate extremes compared to traditional ENSO indices, especially during strong El Niño events.
\end{abstract}

Keywords Precipitation $\cdot$ Hydroclimate $\cdot$ ENSO $\cdot$ Extreme events $\cdot$ Predictability $\cdot$ Western US

\section{Introduction}

Electronic supplementary material The online version of this article (https://doi.org/10.1007/s00382-019-05004-8) contains supplementary material, which is available to authorized users.

Christina M. Patricola

cmpatricola@lbl.gov

1 Climate and Ecosystem Sciences Division, Lawrence Berkeley National Laboratory, Berkeley, CA, USA

2 Department of Earth and Planetary Sciences, University of California, Santa Cruz, Santa Cruz, CA, USA

3 Department of Land, Air and Water Resources, University of California, Davis, Davis, CA, USA

4 Global Climate Adaptation Partnership, Oxford, UK

5 Computational Research Division, Lawrence Berkeley National Laboratory, Berkeley, CA, USA

6 Department of Earth and Planetary Science, University of California, Berkeley, Berkeley, CA, USA
Interannual-to-decadal precipitation variability strongly impacts the people, economy, and ecosystems of the floodand drought-prone western US, where excess precipitation can lead to infrastructure and property damage through flooding and landslides (USGS 1998; CDWR 2017), and precipitation deficit can diminish food production (Maupin et al. 2014; CDFA 2014; Howitt et al. 2014), strain water resources through snowpack reduction (Pierce et al. 2008), and fuel wildfires through enhanced forest mortality (Guarín and Taylor 2005; Dennison et al. 2014; Westerling 2016). Reliable seasonal to multi-decadal predictions and future projections of precipitation are critical to mitigate the impacts of flood and drought, and depend on our ability to understand sources of predictability of hydroclimate extremes.

The dominant mode of interannual sea surface temperature (SST) variability, the El Niño-Southern Oscillation 
(ENSO), has been repeatedly examined as a potential source of predictability for western US precipitation, which shares a boreal winter peak with ENSO (e.g., Tziperman et al. 1998). By some estimates, ENSO provides minimal predictability, driving only $6 \%$ of precipitation variability in California (Savtchenko et al. 2015). However, other studies indicate that certain types of ENSO events can lead to enhanced predictability of precipitation and streamflow (Cayan et al. 1999). In particular, strong El Niño events, characterized by warm SST anomalies (SSTAs) in the eastern-central equatorial Pacific, substantially increase the probability of above-average precipitation in California in observations and climate model simulations (Schonher and Nicholson 1989; Hoell et al. 2016). There is regionality in the ENSOprecipitation relationship, with El Niño tending to have a greater influence on precipitation over southern compared to northern California (Jong et al. 2016; Huang and Ullrich 2017; O'Brien et al. 2019).

Given the documented link between strong El Niño events and extremely wet western US winters, the 2015-2016 El Niño challenged our understanding of the ENSO-precipitation relationship by failing to drive above-average precipitation throughout California despite exhibiting SSTAs in the Niño3.4 region $\left(5^{\circ} \mathrm{S}-5^{\circ} \mathrm{N}\right.$ and $\left.170^{\circ} \mathrm{W}-120^{\circ} \mathrm{W}\right)$ comparable to those during the extreme 1997-1998 and 1982-1983 El Niño events (Lee et al. 2018; Paek et al. 2017). With the role of climate change in modifying ENSO's teleconnections ruled out (Quan et al. 2018), one possible explanation for such behavior is internal atmospheric variability (Kumar and Chen 2017; Chen and Kumar 2018; Deser et al. 2018; Zhang et al. 2018; Cash and Burls 2019). However, El Niño is known to exhibit a wide diversity in spatial patterns of SSTAs (Capotondi et al. 2015; Timmermann et al. 2018), for example with maximum warming located in the Eastern or Central equatorial Pacific, providing a second possible explanation for the precipitation response. Indeed, SSTAs during the 2015-2016 El Niño were located further towards the central Pacific compared with maximum SSTAs in the eastern Pacific during the 1997-1998 and 1982-1983 El Niño events, leading to a weaker deep convection response in the eastern Pacific during 2015-2016 (L'Heureux et al. 2017). Such differences in the zonal shift of tropical deep convection can substantially modify the extratropical wave-train response through which the ENSO-western US precipitation teleconnection operates (Hoerling and Kumar 2002; Yeh et al. 2018).

Therefore, we hypothesize that California failed to experience above-average precipitation during 2015-2016 due to the spatial pattern of El Niño's warming, rather than internal atmospheric variability. Furthermore, we propose that we can improve ENSO's potential for western US precipitation predictability by using a single metric that captures the diversity and extremes of ENSO. Such a metric-the ENSO Longitude Index (ELI) — has been developed recently
(Williams and Patricola 2018). ELI accounts for the nonlinear response of deep convection to SST and considers SSTAs together with the background state, which is characterized by a strong zonal SST gradient associated with the East Pacific cold tongue and West Pacific warm pool. ELI represents the average longitude of tropical Pacific deep convection and is therefore able to distinguish the 2015-2016 El Niño from the extreme 1997-1998 and 1982-1983 El Niño events (Fig. 1a of Williams and Patricola 2018).

Here we address the question: how does the magnitude and spatial pattern of ENSO influence the probability of winter precipitation anomalies over the western US? We consider whether the precipitation response to ENSO is symmetric about ENSO phase, as previous studies indicate that La Niña favors dry years in the western US (Mo and Higgins 1998) whereas others find that the atmospheric response to extreme phases of ENSO is non-linear (Hoerling et al. 1997). In addition, the extremely above-average western US precipitation during the ENSO-neutral conditions of 2016-2017 reiterates that strong El Niño events are not the only driver of wet extremes. Therefore, we also investigate how the spatial patterns of western US precipitation, as well as the atmospheric rivers (ARs) that often deliver it (Payne and Magnusdottir 2014; Rutz et al. 2014; Mundhenk et al. 2016; Hecht and Cordeira 2017; Hu et al. 2017), are constrained by SST and atmospheric variability during ENSO and non-ENSO driven wet years. We use observations together with a statistical model based on Generalized Extreme Value distributions, a large-ensemble of global climate model simulations forced by historical SST, and decades-long regional climate model simulations on a domain encompassing the North Pacific Ocean, most of North America, and the ENSO region to address these questions, with a focus on daily and seasonal precipitation, snowpack, and ARs.

\section{Data and methods}

\subsection{Observations and reanalyses}

We use observed precipitation data from several sources in order to have global coverage, high spatial resolution, a century-long record, and as high as daily temporal resolution. First we describe the gridded products. Global observations over land and ocean are from the $2.5^{\circ} \times 2.5^{\circ}$ resolution monthly Global Precipitation Climatology Project (GPCP) v2.3 dataset (Huffman et al. 1997; Adler et al. 2018), which merges rain gauge observations and satellite data and covers January 1979 through February 2017. Global observations over land are from the $1.0^{\circ} \times 1.0^{\circ}$ resolution monthly Global Precipitation Climatology Centre (GPCC) version 7 dataset covering January 1901 through December 2016 (Schneider et al. 2016). In addition, to provide high-resolution, we use the $0.25^{\circ} \times 0.25^{\circ}$ 
resolution Climate Prediction Center (CPC) Unified GaugeBased Analysis of Daily Precipitation over the contiguous US (CONUS), with daily values from 1 January 1948 through 28 February 2017. For long-term observed monthly precipitation, we use the US Climate Divisional Dataset (Vose et al. 2014), which covers the period January 1895 through December 2016 and provides data by climate division.

In addition to the gridded products, we use station data consisting of measurements of daily total precipitation from the Global Historical Climate Network-Daily (GHCN) over CONUS (Menne et al. 2012a, b). In order to utilize a highquality network of stations with sufficient spatial coverage over the western US, we focus on daily measurements during the wet season from 1951 to 2017. Full details on the quality assurance procedure are given in Risser et al. (2019); after pre-processing, we select the subset of stations that have a minimum of $66.7 \%$ nonmissing daily precipitation measurements between 1950 and 2017. This procedure yields a high-quality set of daily precipitation measurements for $n=5202$ stations over CONUS (Fig. S1). All subsequent analysis of the GHCN data are based on the wet season (December through February) daily maxima. Finally, we use monthly precipitation data from the California Department of Water Resources over the period 1922-2018 (CDWR 2019). The data include the 8-station index, 5-station index, and 6-station index, which include station observations over the Northern Sierra, San Joaquin region, and Tulare basin, respectively. We analyze 12-month averages over the water year, defined as October through the following September.

For analysis of the large-scale circulation response to ENSO, we use the monthly ECMWF twentieth century reanalysis (ERA-20C), which covers the period 1900-2010 and assimilates surface pressure and surface marine winds (Poli et al. 2016). In addition, we use the Modern-Era Retrospective analysis for Research and Applications, Version 2 (MERRA-2; Gelaro et al. 2017) to analyze atmospheric rivers in the historical record, as described in Sect. 2.6.

\subsection{ENSO events}

We identify ENSO events using the December-February (DJF) average of two metrics, the Niño3.4 index and the ENSO Longitude Index (ELI; Williams and Patricola 2018). The Niño3.4 index is based on SST anomalies in a fixed region $\left(5^{\circ} \mathrm{S}-5^{\circ} \mathrm{N}\right.$ and $\left.170^{\circ} \mathrm{W}-120^{\circ} \mathrm{W}\right)$, and therefore does not capture the spatial variations of El Niño events (ENSO diversity). The same is the case for the Niño1+2 index, which is based on SST anomalies in the far Eastern Pacific $\left(0-10^{\circ} \mathrm{S}\right.$ and $\left.90^{\circ} \mathrm{W}-80^{\circ} \mathrm{W}\right)$ and poorly characterizes the response of equatorial Pacific deep convection to La Niña, neutral ENSO, and Modoki events as indicated by the large range of ELI values for Nino1+2 of 1.0 and less (Fig. S2). On the other hand, ELI is an SST-based metric that estimates the average longitude of equatorial Pacific deep convection, and is able to capture ENSO's diversity. In particular, ELI is calculated by first, for each month, calculating the tropicalaverage SST over $5^{\circ} \mathrm{S}-5^{\circ} \mathrm{N}$, to estimate the SST threshold for deep convection, with the basis for this approximation described in Williams and Patricola (2018). We then create a binary mask, assigning 1 to points where SST is at least the convective threshold value, and 0 otherwise. Finally, ELI is the average of all longitudes over which this spatial mask is 1 , within the Pacific basin and over $5^{\circ} \mathrm{S}-5^{\circ} \mathrm{N}$. By characterizing ENSO in this way, ELI accounts for the non-linear response of deep convection to SST and considers SSTAs together with the background state (Williams and Patricola 2018). This means that ELI is more physically meaningful in characterizing the zonal shifts in tropical Pacific deep convection that are important for mid-latitude teleconnections, compared with SSTAs alone.

We compare analyses using these two indices to evaluate whether additional predictability of western US winter precipitation can be gained by considering how the spatial pattern of El Niño's warming influences the atmospheric deep convection response and its teleconnection with precipitation. ENSO events are calculated using the monthly $2.0^{\circ} \times 2.0^{\circ}$ Extended Reconstructed SST v5 (ERSSTv5; Huang et al. 2017) product over DJF of 1885-2017 (Table 1). The definition for strong El Niño (Niño3.4 index $\geq 1.5^{\circ} \mathrm{C}$ ) is based on the analysis in Fig. 1a of Williams and Patricola (2018), which demonstrates that this threshold approximates the distinction between Modoki and "East Pacific" El Niño events, and is the same threshold as used by Hoell et al. (2016). Throughout the paper, the year used to name a DJF average corresponds to January, following the US Geological Survey convention for Water Year.

\subsection{Regional climate model simulations}

Regional climate model simulations were performed with the Weather Research and Forecasting (WRF) model (Skamarock and Klemp 2008), version 3.8.1, which is developed and maintained by the National Center for Atmospheric Research (NCAR). The model is configured with $27 \mathrm{~km}$ resolution over a domain covering $20^{\circ} \mathrm{S}-60^{\circ} \mathrm{N}$ and $130^{\circ} \mathrm{E}-60^{\circ} \mathrm{W}$, which includes CONUS, much of the North Pacific basin, and the ENSO region. The simulations consist of year-long hindcasts from 1981 to 2017, which are initialized in September and run through the full water year (1 October-30 September). Output before 1 October is disregarded as spinup. Each year consists of at least a 5-member ensemble, with a 22-25-member ensemble for selected wet/drought years (i.e., 1982-1983; 1997-1998, 2015-2016, 2016-2017, 2012-2013, 2013-2014, 2014-2015). Initial and lateral boundary conditions are prescribed from 6-hourly $2.5^{\circ} \times 2.5^{\circ}$ National Centers for Environmental Prediction-Department 


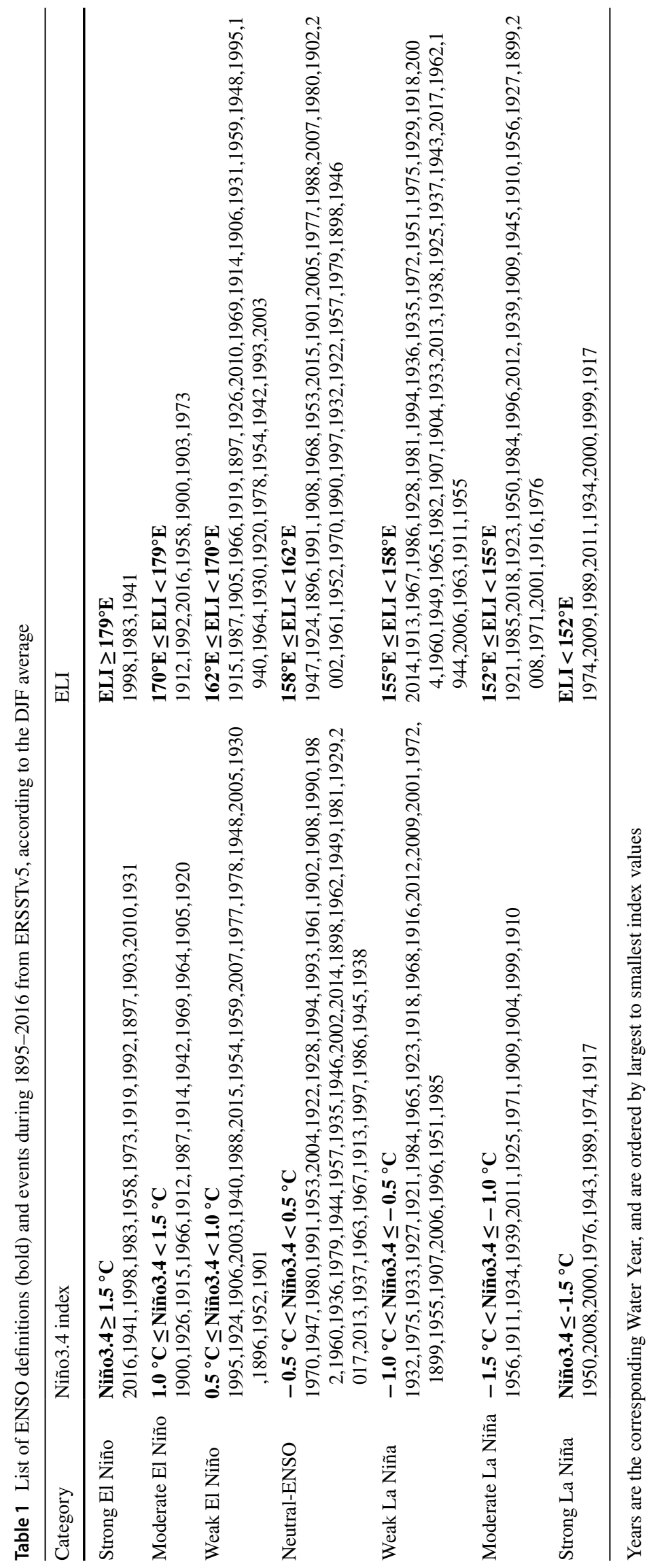


of Energy (NCEP-DOE) Atmospheric Model Intercomparison Project (AMIP)-II Reanalysis (Kanamitsu et al. 2002), and SST is prescribed from the daily $0.25^{\circ} \times 0.25^{\circ} \mathrm{NOAA}$ OI V2 SST (Reynolds et al. 2002).

\subsection{Atmospheric global climate model simulations}

In addition to the regional climate model hindcast simulations, we also analyzed a 50-member ensemble of climate model simulations forced by observed SST, covering January 1959 through February 2018. Contrasting the results from the regional model simulations (in which both SST and lateral boundary conditions are prescribed) to those from the global model (in which just SST is prescribed) provides insight into precipitation variability that is driven by both SST and the large-scale atmospheric circulation, or by SST alone, although we acknowledge that differences may also arise from differences between the models in e.g., physics, resolution, etc. The global model simulations use the $1.0^{\circ}$ resolution Community Atmosphere Model version 5.1 (CAM5.1) and were performed as part of the International CLIVAR Climate of the 20th Century Plus Detection and Attribution project (C20C+D\&A) (Stone et al. 2018). We note that these are the same global model simulations analyzed in Hoell et al. (2016). In addition, the Community Climate System Model version 4 (CCSM4) has demonstrated skill in capturing ENSO-western US teleconnections (DeFlorio et al. 2013).

\subsection{Statistical methods}

We apply the spatial data analysis outlined in Risser et al. (2019) to characterize the spatially-complete climatological distribution of extreme precipitation based on measurements from weather stations, as well as to quantify the relationship between the ENSO indices and daily extremes. An important feature of the Risser et al. (2019) analysis is that it allows one to estimate the distribution of extreme precipitation even for locations where no data are available. Furthermore, their methodology can be used for a large network of weather stations over a heterogeneous spatial domain like the western US, which is critical for the problem at hand. family of distributions. The GEV family of distributions is characterized by three space-time statistical parameters: the location parameter $\mu_{\mathrm{t}}(\mathbf{s}) \in \mathcal{R}$ which describes the center of the distribution; the scale parameter $\sigma_{t}(\mathbf{s})>0$, which describes the spread of the distribution; and the shape parameter $\xi_{t}(\mathbf{s}) \in \mathcal{R}$. The shape parameter $\xi_{t}(\mathbf{s})$ is the most important for determining the qualitative behavior of the distribution of daily rainfall at a given location. If $\xi_{t}(\mathbf{s})<0$, the distribution has a finite upper bound; if $\xi_{t}(\mathbf{s})>0$, the distribution has no upper limit; and if $\xi_{t}(\mathbf{s})=0$, the distribution is again unbounded and the cumulative distribution function is interpreted as the limit $\xi_{t}(\mathbf{s}) \rightarrow 0$ (Coles 2001).

As described in Sect. 1, the goal of this part of the analysis is to characterize the relationship between daily precipitation extremes and the ENSO indices. As such, we use the following statistical model to characterize temporal changes in the GEV statistical parameters:

$\mu_{t}(\mathbf{s})=\mu_{0}(\mathbf{s})+\mu_{1}(\mathbf{s}) x_{t}, \quad \sigma_{t}(\mathbf{s}) \equiv \sigma(\mathbf{s}), \quad \xi_{t}(\mathbf{s}) \equiv \xi(\mathbf{s})$,

where $x_{t}$ represents a wet-season year measurement of either Niño3.4 or ELI. We henceforth refer to $\mu_{0}(\mathbf{s}), \mu_{1}(\mathbf{s}), \sigma(\mathbf{s})$, and $\xi(\mathbf{s})$ as the climatological coefficients for location $\mathbf{s}$, as these values describe the climatological distribution of extreme precipitation in each year.

Using station-specific estimates of the climatological coefficients, we next apply spatial statistical methods (via second-order nonstationary Gaussian processes) to infer the underlying climatology over a fine grid via kriging (again see Risser et al. 2019 for full details). This approach yields fields of best estimates of the climatological coefficients, denoted $\left\{\hat{\mu}_{0}\left(\mathbf{s}^{\prime}\right), \hat{\mu}_{1}\left(\mathbf{s}^{\prime}\right), \hat{\sigma}\left(\mathbf{s}^{\prime}\right), \hat{\xi}\left(\mathbf{s}^{\prime}\right): \mathbf{s}^{\prime} \in \mathcal{G}\right\}$, where $\mathcal{G}$ is the $0.25^{\circ}$ grid of $\mathrm{M}=13,073$ grid cells over CONUS. These estimates can be used to calculate corresponding predictive estimates of the $r$ - year return value for specific values of the ENSO indices, denoted $\widehat{\phi_{r}^{*}}\left(\boldsymbol{s}^{\prime}\right)$, which is defined as the $1-1 / r$ quantile of the distribution of DJF maximum daily precipitation for a value $x^{*}$ of the ENSO index at grid cell $\boldsymbol{s}^{\prime}$, i.e., $P\left(Y^{*}\left(\boldsymbol{s}^{\prime}\right)>\widehat{\phi_{r}^{*}}\left(\boldsymbol{s}^{\prime}\right)\right)=1 / r$, where $Y^{*}\left(\boldsymbol{s}^{\prime}\right)$ represents DJF maxima that arise under ENSO conditions quantified by a fixed index value of $x^{*}$. The return value can be written in closed form in terms of the climatological coefficients:

$\widehat{\phi_{r}^{*}}\left(\boldsymbol{s}^{\prime}\right)=\left\{\begin{array}{l}{\left[\widehat{\mu_{0}}\left(\boldsymbol{s}^{\prime}\right)+\widehat{\mu_{1}}\left(\boldsymbol{s}^{\prime}\right) x^{*}\right]-\hat{\frac{\hat{\sigma}}{\left(s^{\prime}\right)}}\left[1-\{-\log (1-1 / r)\}^{\left.-\hat{\xi}\left(s^{\prime}\right)\right],} \quad \hat{\xi}\left(s^{\prime}\right) \neq 0\right.} \\ {\left[\widehat{\mu_{0}}\left(s^{\prime}\right)+\widehat{\mu_{1}}\left(s^{\prime}\right) x^{*}\right]-\hat{\sigma}\left(s^{\prime}\right) \log \{-\log (1-1 / r)\}, \quad \hat{\xi}\left(s^{\prime}\right)=0}\end{array}\right.$

In short, the essence of the analysis in Risser et al. (2019) is to first obtain estimates of the climatological features of extreme precipitation based on measurements from the weather stations via the Generalized Extreme Value (GEV)
(Coles 2001). While a return value summarizes the magnitude of an event with fixed frequency (i.e., probability $1 / r$ ), we can equivalently quantify the probability of an event with fixed magnitude, also referred to as a return probability 
(in other words, solving $P\left(Y^{*}\left(\boldsymbol{s}^{\prime}\right)>y\right)=\rho_{y}^{*}\left(\boldsymbol{s}^{\prime}\right)$ for fixed $\left.y\right)$. We can again write down an explicit formula for the return probability for a fixed ENSO condition $x^{*}$ in terms of the climatological coefficients (Coles 2001): across the literature, with differences in the meteorological field used, thresholds on those fields, requirements for the geometric footprint of the AR, and object persistence. These choices can ultimately affect conclusions about AR activ-

$\rho_{y}^{*}\left(s^{\prime}\right)=\left\{\begin{array}{l}\left(1-\exp \left\{-\left[1-\xi\left(\mathbf{s}^{\prime}\right)\left(\left[\mu_{0}\left(\mathbf{s}^{\prime}\right)+\mu_{1}\left(\mathbf{s}^{\prime}\right) x^{*}\right]-y\right) / \sigma\left(\mathbf{s}^{\prime}\right)\right]^{-1 / \xi\left(\mathbf{s}^{\prime}\right)}\right\}\right), \quad \xi\left(\mathbf{s}^{\prime}\right) \neq 0 \\ \left(1-\exp \left\{-\exp \left\{\left(\left[\mu_{0}\left(\mathbf{s}^{\prime}\right)+\mu_{1}\left(\mathbf{s}^{\prime}\right) x^{*}\right]-y\right) / \sigma\left(\mathbf{s}^{\prime}\right)\right\}\right\}\right), \quad \xi\left(\mathbf{s}^{\prime}\right)=0\end{array}\right.$

We again reiterate that these quantities are predictive in the sense that we use the full time series of DJF maxima for each station to quantify the relationship between the ENSO indices and extreme precipitation and then plug in fixed values of the ENSO indices to estimate the return value/probability under such conditions.

Uncertainty measures are quantified nonparametrically using data-driven, resampling-based approaches, wherein seasons of data are resampled in a consistent manner for all weather stations to preserve spatial information in the daily precipitation measurements. To estimate the uncertainty in our estimated return values (or any other quantity) we use the block bootstrap (wherein "blocks" or years of data are resampled in the same way for all stations in order to preserve the spatial relationships; see Risser et al. 2019 for further details) which is important for quantifying uncertainty in this analysis since first estimating station-specific extreme climatology and then smoothing spatially does not explicitly account for the spatial dependence in the daily measurements of precipitation, or the so-called "storm dependence" (dependence due to the spatial coherence of storm systems; Risser et al. 2019 verify that this approach appropriately accounts for storm dependence).

Finally, we can use the ratio of return probabilities (also referred to as the "risk ratio"; see Risser et al. 2017) to compare the likelihood of extreme events occurring under contrasting ENSO states, e.g. strong El Niño versus strong La Niña. Here, the risk ratio for a particular grid cell is defined as $R R\left(s^{\prime}\right)=\frac{\rho_{y}^{(E N)}\left(s^{\prime}\right)}{\rho_{y}^{(L N)}\left(s^{\prime}\right)}$ where $\rho_{y}^{(E N)}\left(s^{\prime}\right)$ is the return probability for a strong El Nino (quantified by a particular index value; see Table 1) and $\rho_{y}^{(L N)}\left(\boldsymbol{s}^{\prime}\right)$ the corresponding return probability for a strong La Niña. The interpretation of $R R\left(s^{\prime}\right)$ is as follows: a risk ratio of less than one means the event $y$ is more common under La Niña conditions, while a risk ratio of greater than one means the event is more common under El Niño conditions.

\subsection{Atmospheric river tracking}

We use the Tempest software package (Ullrich and Zarzycki 2017) to identify ARs in the MERRA-2 and the WRF simulations. Algorithms for AR detection are substantially varied ity, as demonstrated in a comprehensive intercomparison of AR detection algorithms (Shields et al. 2018; Ralph et al. 2019a). In general, these algorithms rely on detection of ARs using integrated vapor transport (IVT), which incorporates both water volume and flow speed. The Tempest AR tracking algorithm uses the following criteria to detect AR conditions at a grid point:

- The point must be poleward of 20 degrees latitude, to mask out tropical vapor fluxes.

- The IVT must exceed $250 \mathrm{~kg} / \mathrm{m} / \mathrm{s}$ - a typical low-bar threshold for AR conditions based on the formal definition of ARs (Ralph et al. 2019b).

- The Laplacian of the IVT, computed using an 8-point numerical stencil with a radius of 5 degrees, must be less than $-15.23 \mathrm{~kg} / \mathrm{m} / \mathrm{s} / \mathrm{deg}^{2}\left(-50,000 \mathrm{~kg} / \mathrm{m} / \mathrm{s} / \mathrm{rad}^{2}\right)$. This criteria ensures that the AR object is sufficiently long and narrow.

- At least 40 adjacent grid points $\left(12.5 \mathrm{deg}^{2}\right)$ must meet the above criteria, determined via a flood-fill algorithm, so as to mask out minor detections of localized IVT maxima.

In general, Tempest produces AR statistics that are very close to the tracking algorithm ensemble median, which suggests that it does not greatly overestimate or underestimate true AR statistics (Rutz et al. 2019).

\section{Results}

\subsection{Winter precipitation}

As discussed in the introduction, the 2015-2016 El Niño challenged our understanding of the relationship between ENSO and western US precipitation. Among the strongest four observed El Niño events (as defined by the Niño3.4 index), it was the only one that did not produce substantially above-average precipitation over California (Fig. 1a-d and Table S1), resulting in a seasonal forecast bust (L'Heureux et al. 2017; Wang et al. 2017a). Specifically, precipitation during the water years associated with the 1940-1941, 1982-1983, and 1997-1998 El Niño events exceeded the 

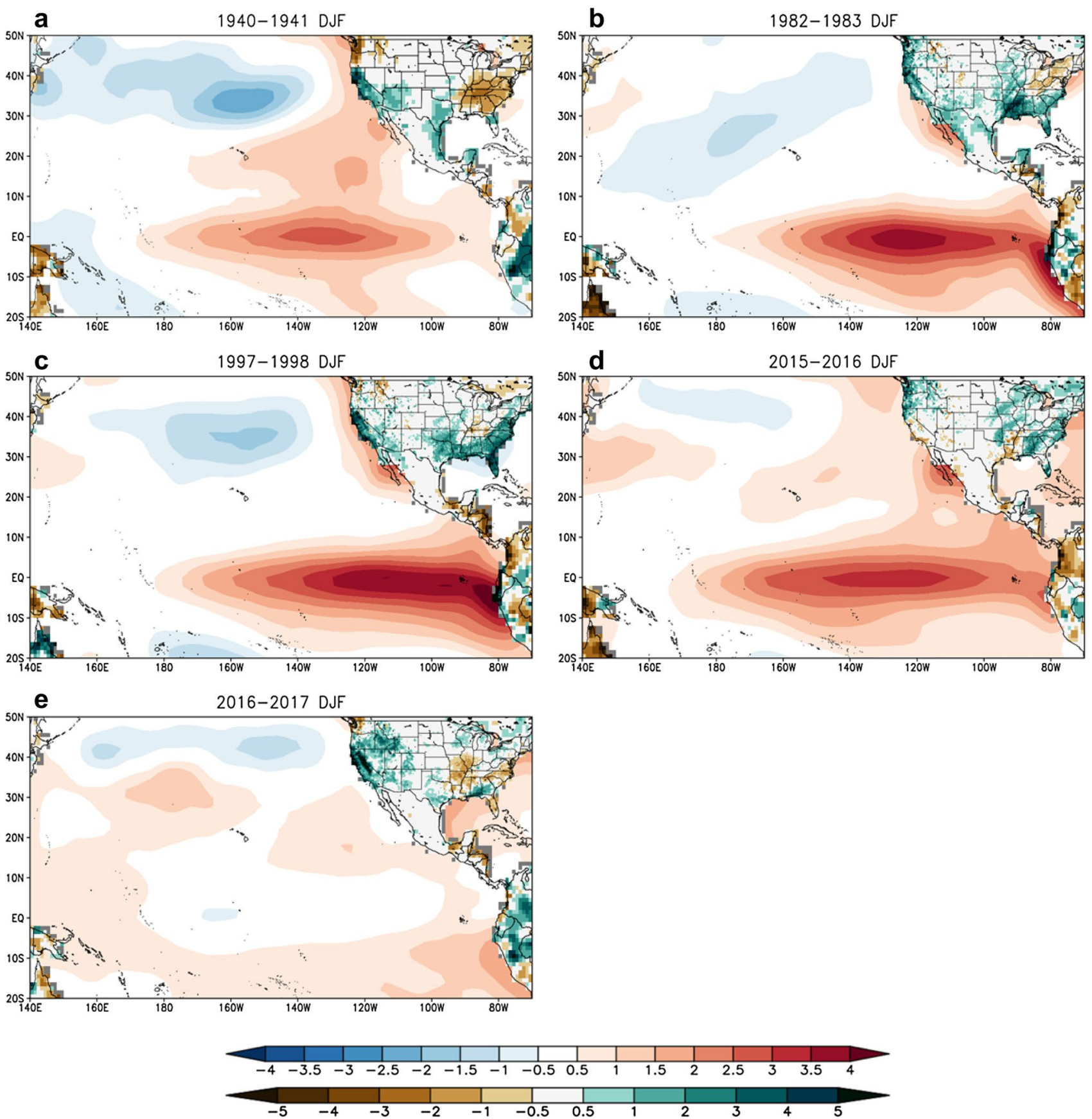

Fig. 1 Observed SST anomalies (K; blue-red shading) and precipitation anomalies (mm/day; brown-green shading) averaged DJF from the four strongest observed El Niño events according to the Niño3.4 index: a 1940-1941, b 1982-1983, c 1997-1998, and d 2015-

90th, 78th, and 88th percentile according to the 8-station, 5-station, and 6-station index, respectively, whereas the water year centered on the 2015-2016 El Niño event ranked in the 69th, 59th, and 51st percentile, respectively (Table S1).

We investigate the hypothesis that this unexpected "failure" of extremely wet conditions during the 2015-2016
2016, and from the neutral-ENSO event e 2016-2017. SST is from ERSSTv5 and terrestrial precipitation is from GPCP, except for precipitation over CONUS which is from CPC when available. Anomalies are relative to the DJF 1950-2016 climatology

winter was due to the location of El Niño's SST warming, rather than internal atmospheric variability, using the largeensemble of SST-forced global climate model hindcasts. An ensemble-mean precipitation response that resembles the observed suggests that the observed precipitation pattern was driven largely by SST forcing, whereas an ensemblemean response that does not resemble the observed suggests 

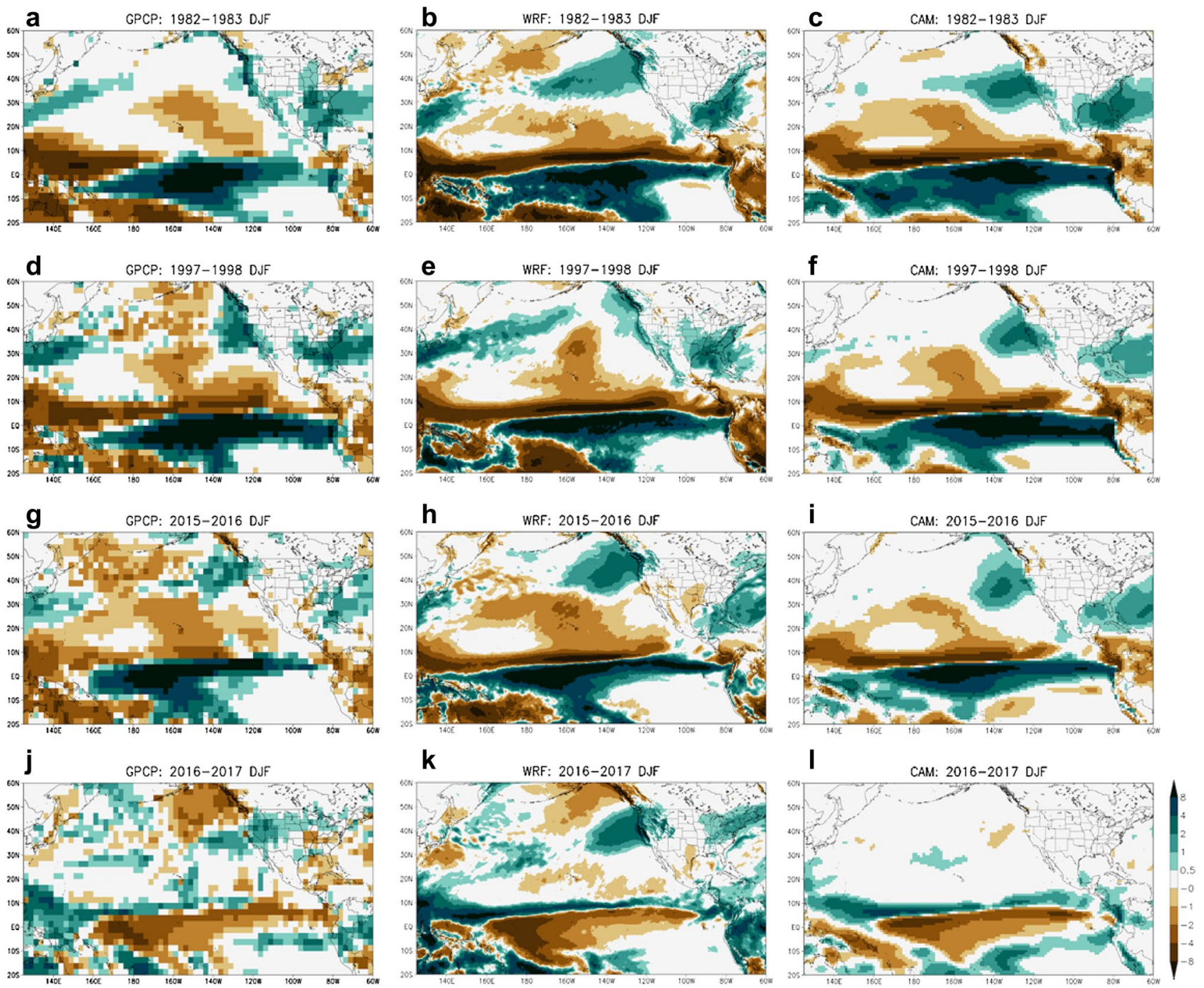

Fig. 2 Precipitation anomaly averaged DJF of 1982-1983, 19971998, 2015-2016, and 2016-2017 from the (a, d, g, j, respectively) GPCP observations, (b, e, h, k, respectively) WRF simulations, and

the observed precipitation pattern was driven by internal atmospheric variability (in the absence of systematic model biases).

The global model reproduces the observed wet conditions over California during the 1982-1983 (Fig. 2a and c) and 1997-1998 (Fig. 2d and f) El Niño events, as well as the observed near to moderately above average precipitation over California during the 2015-2016 El Niño (Fig. 2g and $\mathrm{i}$ ), indicating that the precipitation pattern in all three cases was driven by SST. This finding is supported by Siler et al. (2017), who found that SSTAs outside the Niño3.4 region contributed to the observed precipitation pattern during 2015-2016, but it is inconsistent with other studies that found internal atmospheric variability played a leading role (Chen and Kumar 2018; Deser et al. 2018; Zhang et al. 2018). (c, f, i, l, respectively) CAM simulations relative to the 1981-2016 DJF climatology (the longest period of overlap among the datasets)

The importance of SST forcing in driving western US precipitation during 2015-2016 is in contrast to the 2016-2017 season, in which the global model reproduces the observed precipitation response over the tropics, but fails to capture the record-breaking precipitation over the western US (Fig. $2 \mathrm{j}$ and 1 ), despite demonstrated skill in simulating other similarly high-precipitation years. On the other hand, the regional model hindcast reproduces the observed 2016-2017 precipitation anomalies well (Fig. 2k), likely in part owing to the additional constraint on the atmospheric circulation through the lateral boundary conditions. Combined, the global and regional climate model simulations provide strong evidence that internal atmospheric variability drove the western US precipitation pattern during 2016-2017, which was indeed characterized by neutral ENSO conditions. 

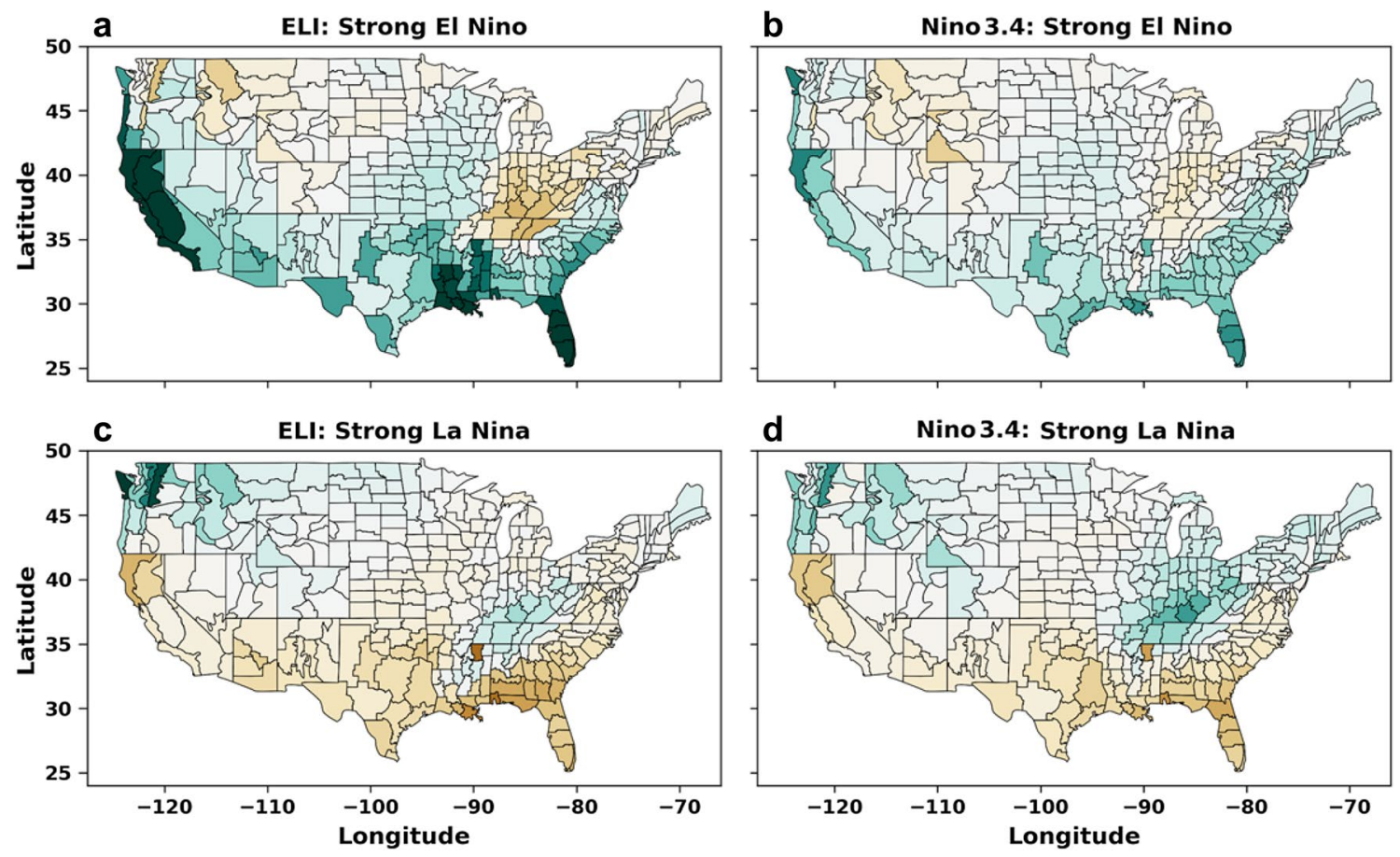

d Nino 3.4: Strong La Nina
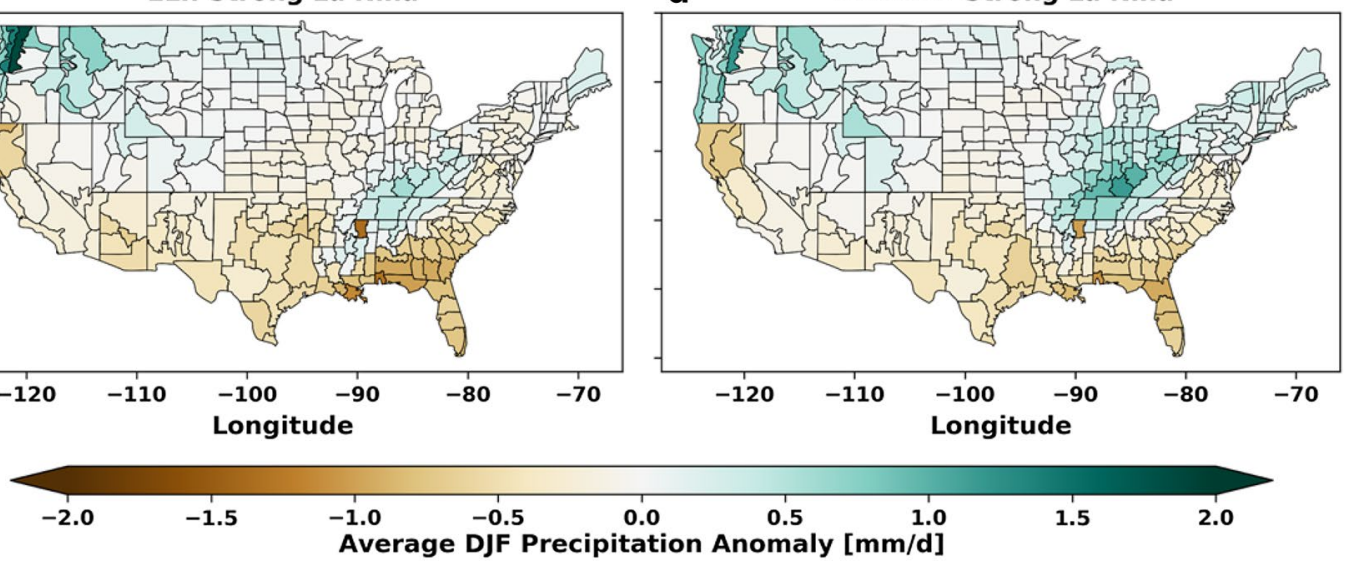

Fig. 3 Observed precipitation anomalies ( $\mathrm{mm} /$ day) averaged DJF relative to the 1979-2016 period from the US Climate Divisional Dataset for composites according to strong El Niño events as defined by a

Having established SST forcing as the primary driver of the western US precipitation pattern during the 2015-2016 winter, we investigate the idea that the corresponding El Niño event's spatial pattern played a leading role in the nearaverage precipitation over California. Although this El Niño event was the strongest on record in terms of SST anomaly, as measured by the Niño3.4 index, it ranked as a moderate El Niño event by the zonal location of equatorial deep convection, as measured by ELI (Table 1). Composites of precipitation anomalies corresponding to strong El Niño and strong La Niña events, with a comparison for ENSO events based on ELI and the Niño3.4 index, are shown from the US Climate Divisional observations (Fig. 3), GPCC observations (Fig. 4a-d), and global climate model simulations (Fig. $4 \mathrm{e}-\mathrm{h}$ ). We consider the two observational products so that we can include the greatest number of observed ENSO events and analyze the precipitation response over both the ocean and land, respectively.

It is apparent that the positive winter precipitation anomaly over the western US during strong El Niño events is greater for events based on ELI than on the Niño3.4 index. The fact that both observational products (which have a relatively limited sample size) and the large-ensemble global
ELI and $\mathbf{b}$ the Niño3.4 index and strong La Niña events as defined by c ELI and $\mathbf{d}$ the Niño3.4 index. ENSO events are listed in Table 1

model simulations (which can contain model biases) produce the same result strengthens confidence in this conclusion.

We note that due to the rarity of strong El Niño as revealed by ELI, there are only three observed events in the observational composite, compared with 12 events for strong El Niño according to the Niño3.4 index. Therefore, we examined the sensitivity of the precipitation response to "strong El Niño" definition by restricting the observational composite analysis to the three strongest events (Fig. S2). The results are similar to the threshold-based analysis, providing support that the precipitation response is related to considering ENSO from the physically-based ELI perspective, rather than an artefact of sample size differences.

Since previous studies have suggested that La Niña is favorable for western US drought, we compare the precipitation signals between composites of strong El Niño and strong La Niña events. Both observations and the global model indicate that the western US winter precipitation response is asymmetric about ENSO phase, that is, the magnitude of the wet anomalies during strong El Niño events substantially exceeds the magnitude of the dry anomalies during strong La Niña events for anomalies both in terms of $\mathrm{mm} /$ day (Figs. 3 and 4) and percent (Fig. S4). 


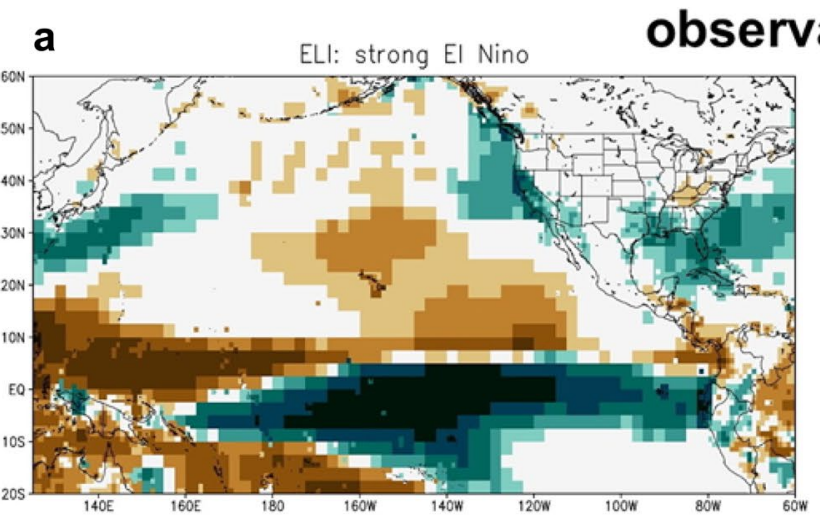

ations

b
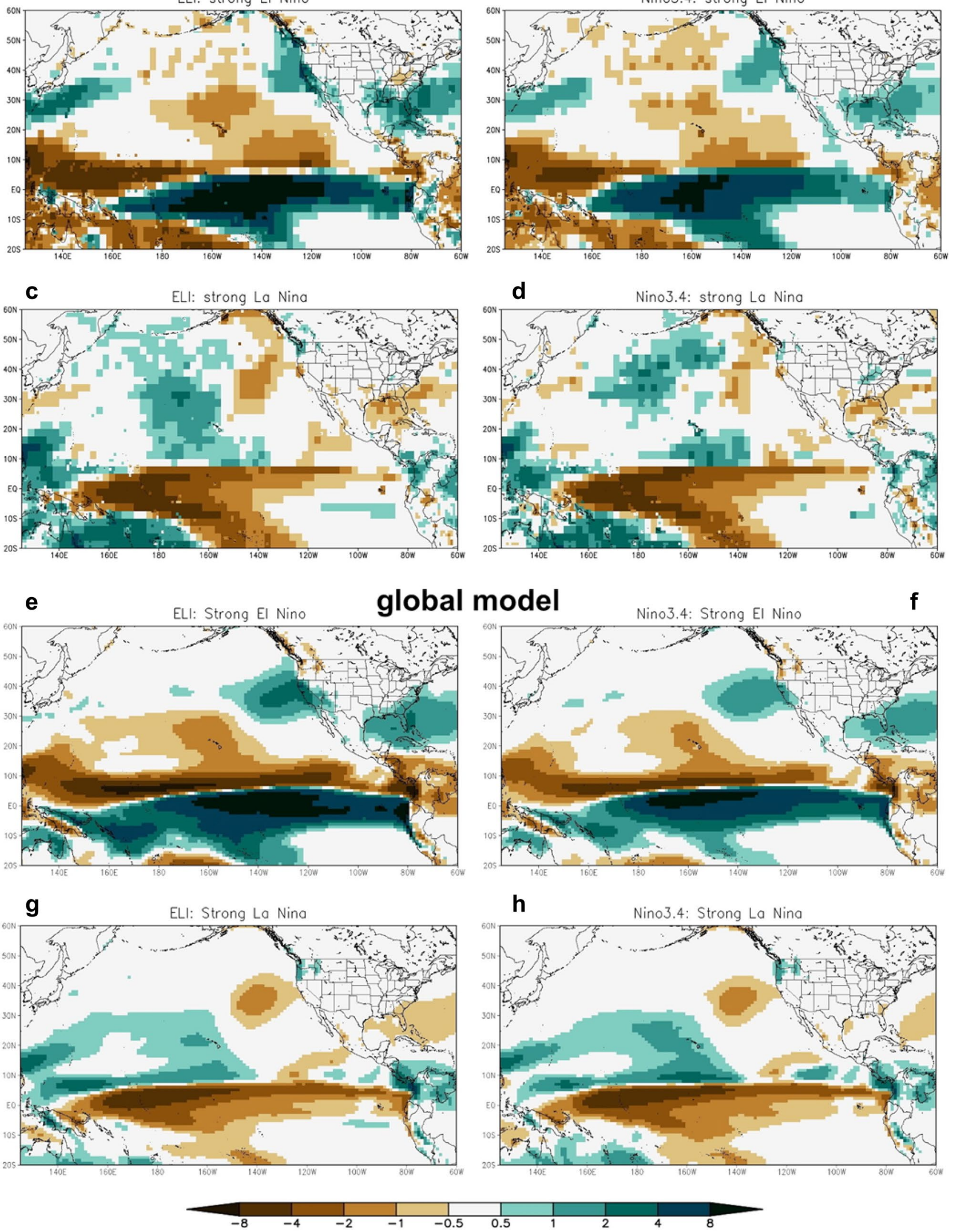
4Fig. 4 Precipitation anomaly ( $\mathrm{mm} /$ day) averaged DJF from the GPCC dataset over land and the GPCP dataset over ocean for composites according to strong El Niño events as defined by a ELI and $\mathbf{b}$ the Niño3.4 index and strong La Niña events as defined by $\mathbf{c}$ ELI and $\mathbf{d}$ the Niño3.4 index relative to the 1979-2016 DJF climatology. e-h As in a-d, but from the 50-member ensemble of CAM simulations. ENSO events are listed in Table 1

Although the focus of this study is the western US, we note that the Climate Division observations also indicate a stronger precipitation response for ELI-based strong El Niño events compared to the Niño3.4 index over the southwestern, central, and southeastern US (Fig. 3a and b). Some of the precipitation anomalies, especially those over the Central US where climatological precipitation is relatively weak (Fig. $\mathrm{S} 5$ ), are even more pronounced when expressed in terms of percent (Fig. S4).

One of the benefits of using the large-ensemble of global climate simulations is that it contains enough data to evaluate the probability density functions (PDFs) of DJF precipitation conditional on various ENSO conditions (Fig. 5), similar to the analysis in Fig. 3 of Hoell et al. (2016), which was performed just before the 2015-2016 El Niño event. This allows us to understand how the likelihood of wet or dry conditions responds to ENSO, accounting for variations due to internal atmospheric variability. It is clear from the PDFs of winter precipitation that strong El Niño favors wetter than average seasons over southern, central, and northern California. Furthermore, the precipitation distributions are shifted even more towards extremely wet seasons for strong El Niño events defined using ELI, compared with the Niño3.4 index. This indicates that compared with ELI, using the Niño3.4 index to define strong El Niño events results in a decreased probability of above-average winter precipitation, suggesting that considering ENSO events from an ELI perspective provides better seasonal predictability of western US precipitation. Likewise, compared with ELI, using the Niño3.4 index to define strong El Niño events is more likely to result in "unexpected" dry anomalies over California. Over western Oregon and western Washington, the precipitation distribution during strong El Niño events is slightly shifted towards drier seasons, with little dependence on ENSO event definition.

As also indicated by the ensemble-mean winter precipitation responses, the response in the precipitation PDFs is asymmetric about ENSO phase, with a more substantial PDF shift during strong El Niño events compared with strong La Niña (Fig. 5). In addition, there is regional dependence in the PDFs of winter precipitation, with substantial shifts towards wetter-than-average conditions during strong El Niño events over all of California, but shifts toward drier-than-average conditions during strong La Niña events only over southern and central California.

\subsection{Daily precipitation extremes}

Whereas seasonal precipitation extremes have important implications for water resources, daily precipitation extremes can pose dangerous and costly hazards including flooding and landslides (e.g., White et al. 2019). Therefore, we evaluate the relationship between ENSO and the 10 -year return value of daily precipitation (i.e., the daily precipitation amount that is expected to occur once every 10 years). We use the GHCN station data which provides a long record of point observations best suited for analysis of such extremes.

The 10-year return value of daily winter precipitation for the full observational record (1950-2017, i.e., including all ENSO phases) shows the greatest values over the western US, especially over mountain regions, as well as the Gulf Coast states of Louisiana, Alabama, and Mississippi (Fig. 6a). Strong El Niño events lead to a substantial and meaningfully non-zero increase (i.e., the $90 \%$ confidence interval does not include zero; denoted by hatching) in 10-year return values over the western US, with a signal that is substantially greater for ENSO events defined using ELI compared to the Niño3.4 index (Fig. 6c). This suggests that ELI may provide better predictability for daily extreme precipitation during strong El Niño events compared with the Niño3.4 index, as was the case for seasonal precipitation. In addition, strong La Niña events drive a decrease in the 10-year return values of western US daily precipitation (Fig. 6b), however the magnitude of the response is weaker than that for strong El Niño for events defined by ELI. This suggests that although the sign of the response of daily precipitation extremes is symmetric about ENSO phase, the magnitude of the response is asymmetric in terms of anomalies in 10-year return values. Finally, we note that although the western US precipitation response to strong La Niña is slightly greater for ENSO events defined using the Niño3.4 index compared to ELI, the difference between strong El Niño and strong La Niña over the western US is better described by ELI (as evidenced by risk ratio estimates that are larger in magnitude, i.e., greater than 1 and less than 1; Fig. 6d).

Although the western US is our focus, we note similar results over the southeastern and south-central US. In addition, the results for the 10-year return values are similar for 20- and 50-year return values (i.e., events that are even more extreme), although with greater uncertainty.

\subsection{Snowpack}

Mountain snowpack, or its snow water equivalent (SWE), is one of the primary natural storage mechanisms for water resources in the western US (Palmer 1988; Mote et al. 2005, 2018). However, mountain snowpack is susceptible to large 


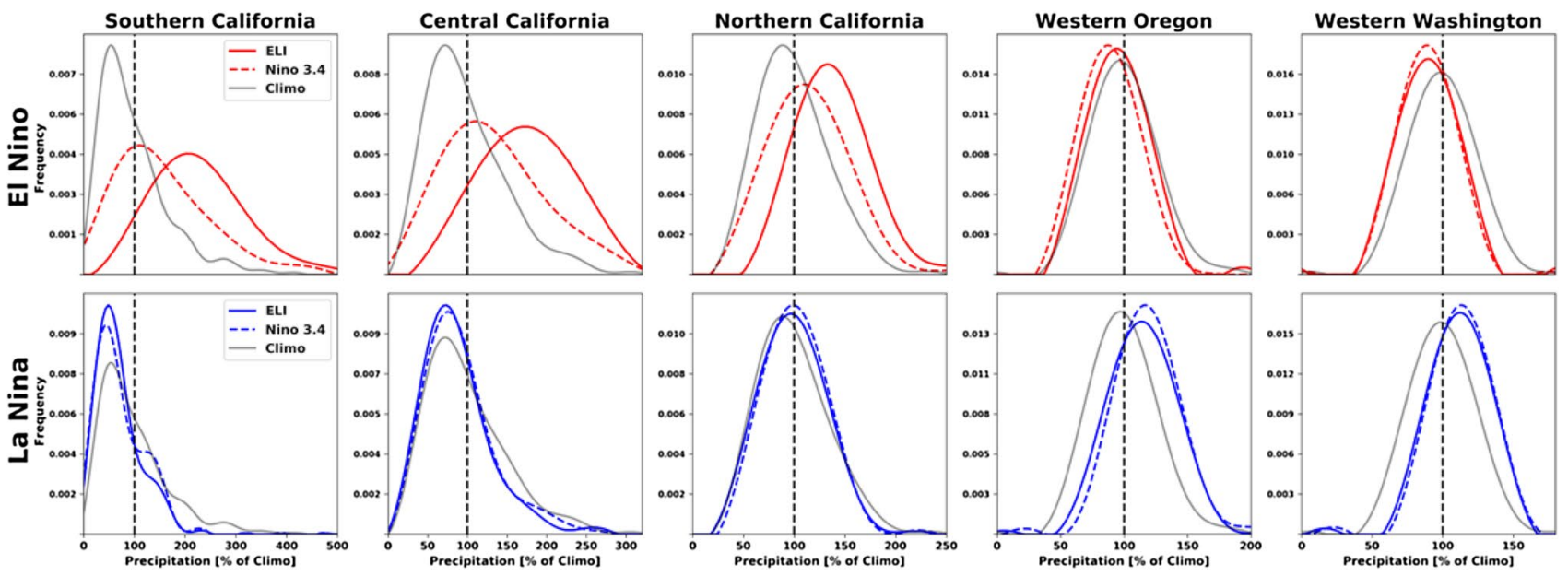

Fig. 5 Probability density functions of average DJF precipitation as percent of 1979-2016 climatology (grey) from the global model simulations. Strong El Niño events (top/red), and strong La Niña events (bottom/blue), defined using ELI (solid) and Niño3.4 (dashed) averaged over various geographical regions of the western US shown in Fig S6 interannual variability due to fluctuations in storm landfall location, phase, intensity, and surface temperatures throughout the water year (Bales et al. 2006; Guan et al. 2010; Kapnick and Hall, 2012; Pierce and Cayan, 2013; Guan et al. 2016; Harpold et al. 2017; Musselman et al. 2017, 2018; Rhoades et al. 2018). This large fluctuation is connected with ENSO (Cayan 1996) and has considerable socioeconomic impacts associated with water availability and seasonal recreation (Hagenstad et al. 2018). Water resource managers often look to predictions of ENSO as an indication of upcoming snow season health. However, the connection between ENSO and western US snowpack totals remains opaque, potentially leaving millions of acre-feet of seasonal storage up to chance (Kapnick et al. 2018).

Due to the connections between strong El Niño and western US precipitation (Sects. 3.1 and 3.2) and IVT and ARs (Sect. 3.4), we analyze the influence of strong ENSO events on SWE at both seasonal and daily temporal scales. This is done to understand the large-scale influence of strong ENSO events on mountain snowpack storage as well as daily fluctuations in the accumulation, peak timing, and melt seasons of snowpack. Figure 7 shows the DJF SWE anomalies during strong El Niño and La Niña years (defined using ELI or the Niño3.4 index) relative to the 1981-2017 climatology from the ensemble of WRF simulations. We use the WRF simulations for analysis of SWE because $27 \mathrm{~km}$ resolution better represents snow and mountainous terrain compared with the $1^{\circ}$ global model resolution, and because the largeensemble of WRF hindcasts provides a greater sample size of ENSO events compared to observations. For context, Fig. S7 shows these DJF SWE anomalies as a percentage of climatology. The way in which ENSO is defined results in major differences in the response of SWE to strong El Niño.
This difference is most pronounced in the Sierra Nevada, the Cascades, and throughout the Intermountain West where the sign and strength of the DJF SWE anomaly depends on ENSO measure (Fig. 7 and Fig. S7). On the other hand, during strong La Niña years there is a consistent spatial pattern in anomalous DJF SWE between the two ENSO indices across much of the western US. In the Cascades and Rockies, there is a positive DJF SWE anomaly for both indices, whereas in the Sierra Nevada, there is a north-south gradient in positive and negative DJF SWE anomalies (that is more pronounced according to the Niño3.4 index). However, these anomalies are computed for the non-shoulder months of the winter season and therefore could be missing important early- and late-winter SWE responses to ENSO.

To better understand how ENSO index choice influences SWE anomalies, and how this might shape the accumulation, peak timing, and melt season over the water year, Fig. 8 presents the daily average SWE for strong El Niño, strong La Niña, and climatological conditions. For the mountainous regions of the western US, ELI exhibits more of an average snow season during strong El Niño events, whereas the Niño3.4 index shows a below-average snow season. In addition, peak SWE timing occurs earlier (later) during strong El Niño (La Niña) events by $-5(+5)$ days, or February 27 (March 9), for events defined using ELI compared with climatological conditions. For the Niño3.4 index, differences in peak SWE timing are more contrasting with strong El Niño (La Niña) events occurring - $14(+4)$ days, or February 18 (March 8), from climatological conditions. This difference in peak SWE timing between ENSO definitions indicates differences in the phase and/or magnitude of precipitation and AR landfall location during the accumulation season, as demonstrated in other sections. 
a $10-$ year return value, DJF climatology $(\mathrm{mm})$

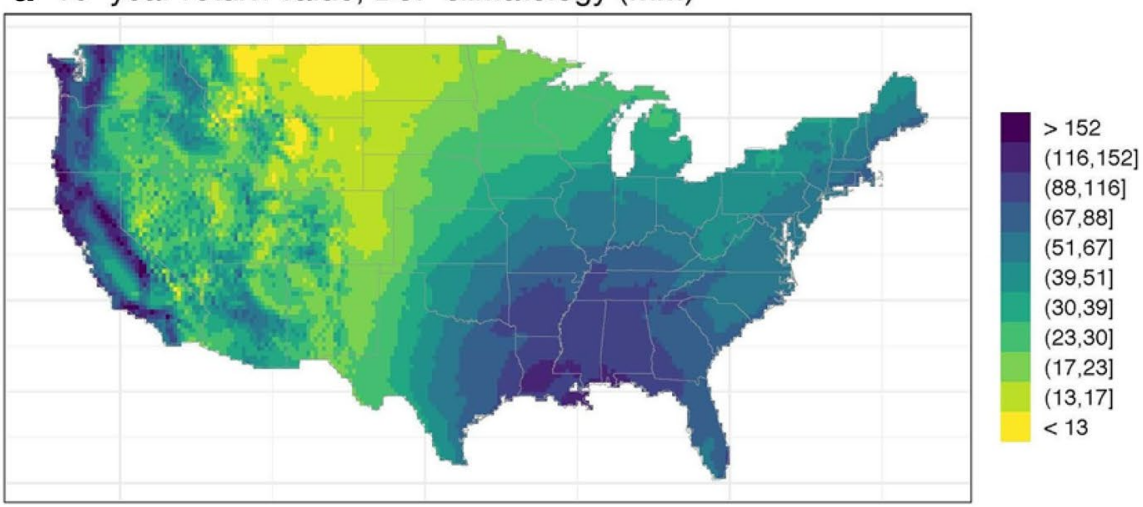

b Strong La Nina 10-year return value, relative to DJF climatology $(\mathrm{mm})$

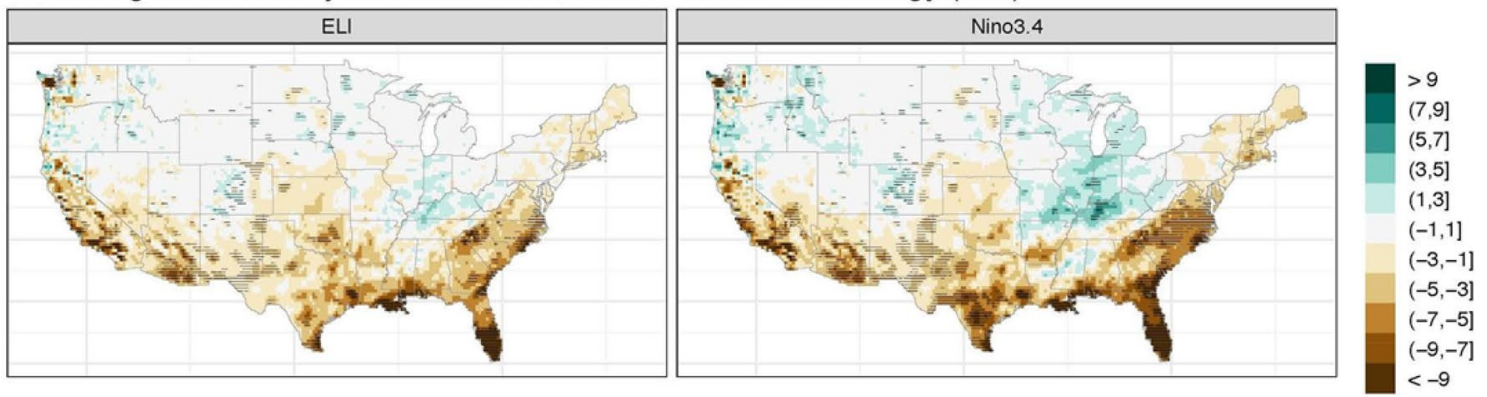

C Strong El Nino 10-year return value, relative to DJF climatology ( $\mathrm{mm}$ )
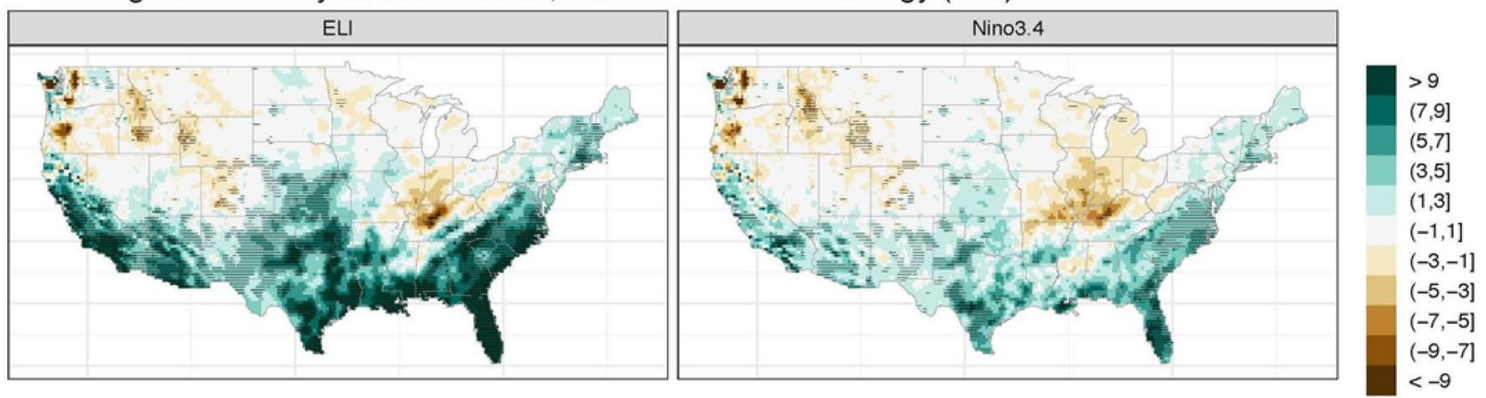

d Risk ratio comparing strong El Nino vs. strong La Nina (event shown in panel a.)
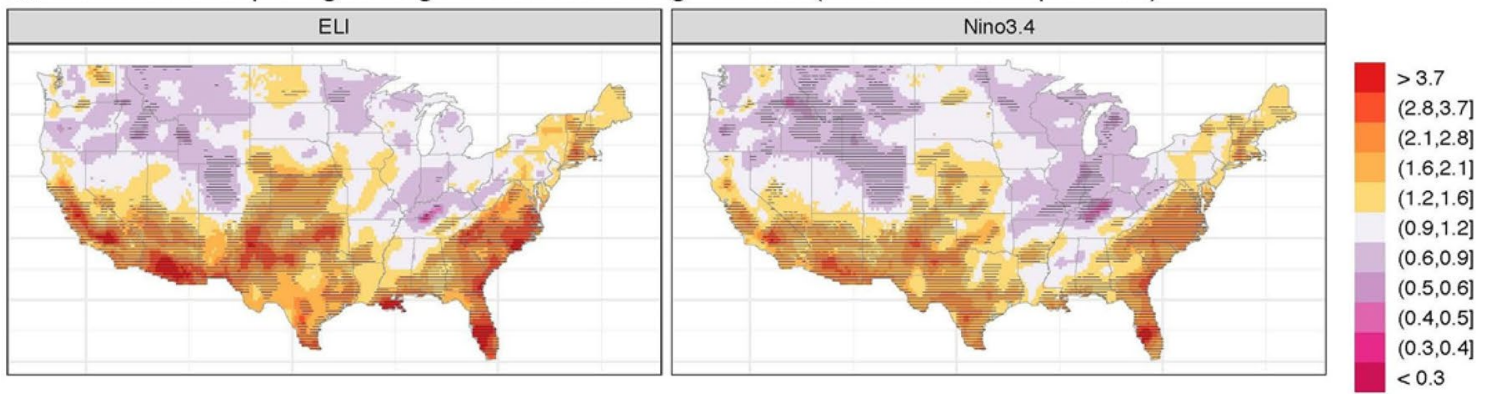

Fig. 6 a 10-year return value for DJF climatology (i.e., averaging over 1950-2017); b difference in the 10-year return value for a strong La Niña year vs. the climatology (following definitions in Table 1, i.e., $\mathrm{ELI}=152^{\circ} \mathrm{E}$ and Niño3.4 $=-1.5^{\circ} \mathrm{C}$ ); $\mathbf{c}$ difference in the 10 -year return value for a strong El Niño year vs. the climatology (following definitions in Table 1, i.e., ELI $=179^{\circ} \mathrm{E}$ and Niño3. $4=1.5^{\circ} \mathrm{C}$ ); $\mathbf{d}$ the risk ratio for a strong El Niño vs. a strong La Niña (again quantified as in $\mathrm{b}$ and c) for the 10-year climatological return value. In b-d, hatching indicates grid cells where the $90 \%$ confidence interval does not include 0 (for the return value differences) or 1 (for the risk ratio). Data are from the GHCN stations 


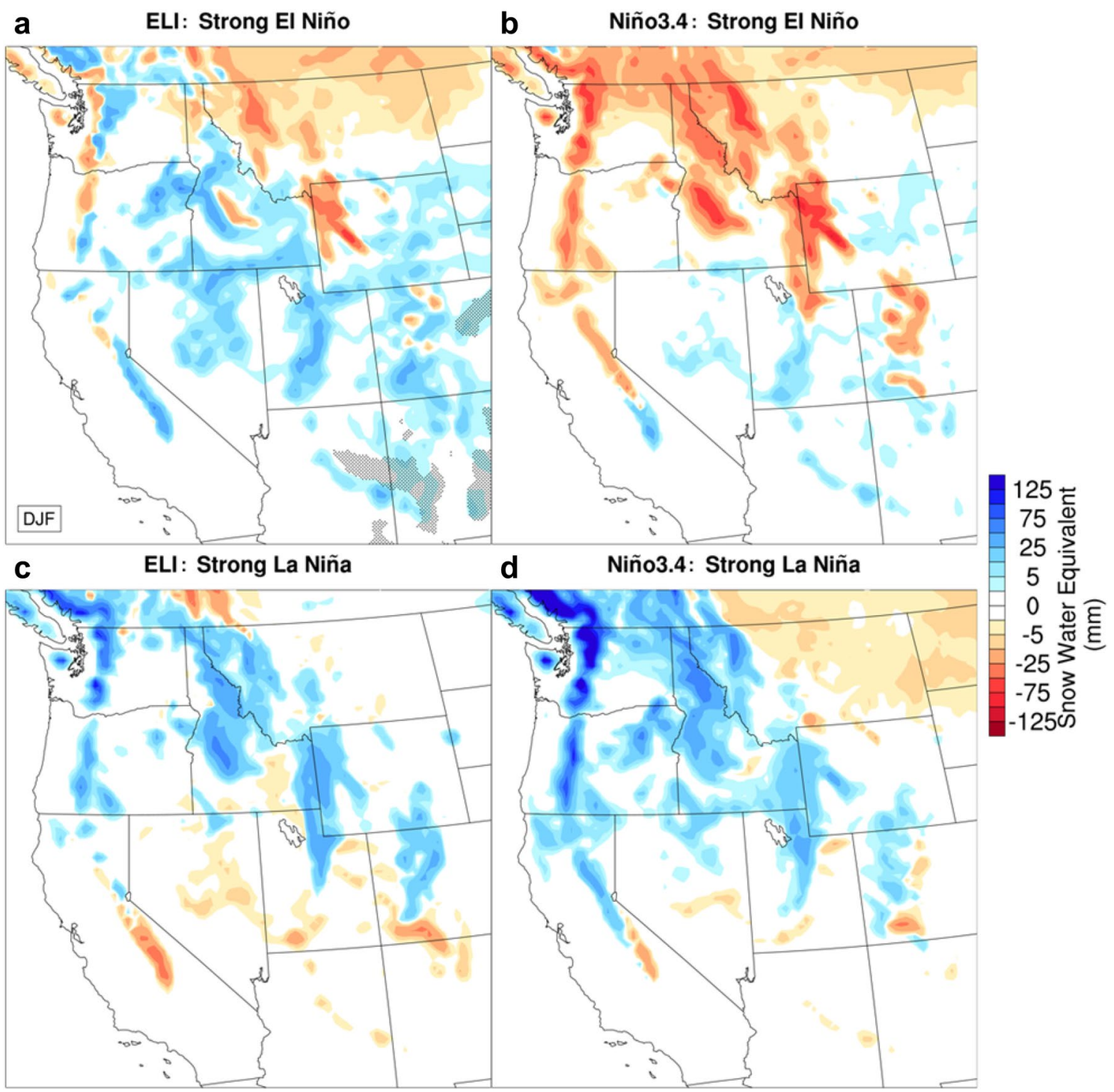

Fig. 7 Anomalies in DJF snow water equivalent (SWE; mm) for composites of strong El Niño events as defined by $\mathbf{a}$ ELI and $\mathbf{b}$ the Niño3.4 index and strong La Niña events as defined by $\mathbf{c}$ ELI and $\mathbf{d}$

Over the California Sierra Nevada, DJF SWE anomalies during a given ENSO phase change sign depending on whether events are defined using ELI or Niño3.4 (Fig. 7). With ELI, SWE over the Sierra Nevada is more consistently positive (negative) during strong El Niño (La Niña) events, whereas the anomaly is mixed for the Niño3.4 index. Although the DJF SWE anomalies are not statistically significant $(p=0.01)$, there is an appreciable difference in the total water volume of the snowpack. In particular, the difference in peak SWE over the Sierra Nevada is $61.4 \mathrm{~mm}$ during strong El Niño events defined using ELI compared with the historical climate average (Fig. S8), which translates to 2.6 million-acre-feet (MAF) in snowpack storage. (The calculation for MAF is outlined in the Supplemental Information.) the Niño3.4 index from WRF hindcast simulations. Anomalies are relative to the 1981-2017 WRF simulated climatology. ENSO years are defined in Table 1. Stippling represents a z-score $>2.58(p=0.01)$

This is roughly equivalent to half of the total storage capacity of California's largest reservoir, Lake Shasta, or one-third of the 8.3 MAF of annual water demand by the urban sector of California (Hanak et al. 2015). Thus, the regional SWE response during strong El Niño years translates to considerable impacts on the water sector, particularly for California and the Pacific Northwest.

\subsection{Large-scale circulation and atmospheric rivers}

Given that ENSO drives western US (and global) precipitation and temperature patterns via large-scale atmospheric teleconnections (Horel and Wallace 1981; Ropelewski and Halpert 1987; Kiladis and Diaz 1989; Dai and Wigley 2000; 


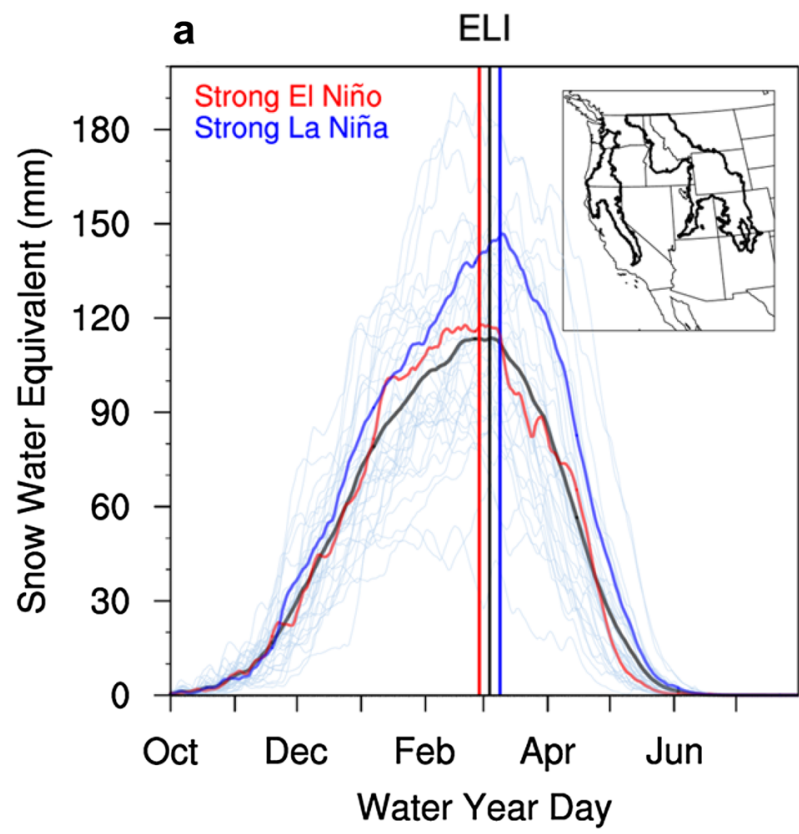

b $\quad$ Niño3.4

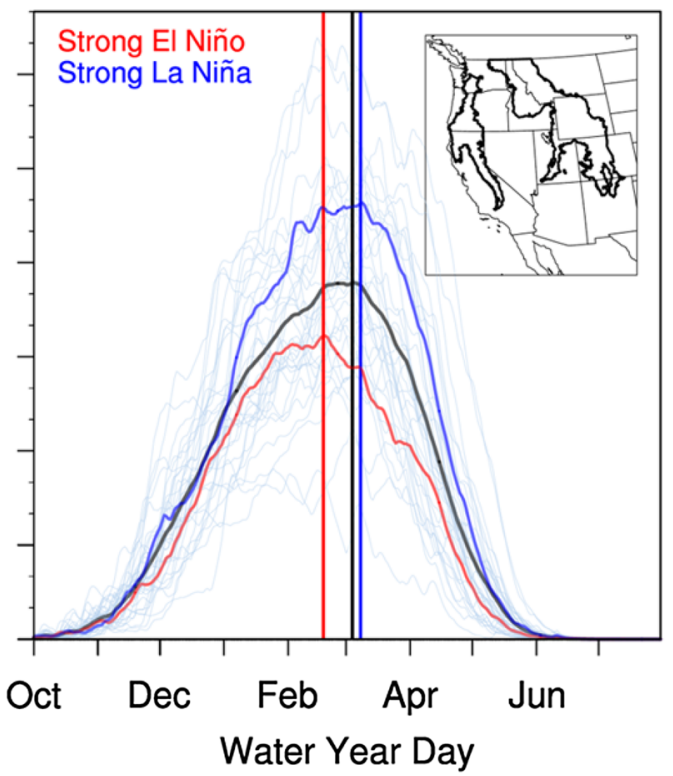

Fig. 8 WRF simulated daily average snow water equivalent (SWE; $\mathrm{mm}$ ) across water years 1981-2017. Blue (red) lines indicate strong La Niña (El Niño) events defined using a ELI and b the Niño3.4 index. Gray lines represent individual years and the black line represents the daily climate average across all water years. SWE daily

McPhaden et al. 2006), we next investigate how the largescale circulation response to ENSO events differs according to ENSO definition. During El Niño, anomalously warm SSTs in the tropical eastern Pacific shift deep convection eastward (Bjerknes 1969). The convective heating anomaly excites a Rossby wave-train that propagates into the extratropics and modifies global weather patterns (Held et al. 1989; Alexander et al. 2002; Deser et al. 2017).

Figure 9 shows the response in DJF geopotential height at 250-hPa from the ERA-20C reanalysis for composites corresponding to strong El Niño and La Niña events defined by ELI and the Niño3.4 index, with marks representing the average longitude of deep convection as estimated by ELI for the years making up each composite. The large-scale circulation response to strong El Niño events is qualitatively similar for events defined by ELI and the Niño3.4 index, with an anomalous anticyclone over the subtropical Pacific and Northeastern North America and an anomalous cyclone over the Northeast Pacific (corresponding to a southward shift of the climatological winter Aleutian Low; Fig. S9) and Southern US. However, strong El Niño events as defined by ELI (Fig. 9a) exhibit a deepening and an eastward extension of the Aleutian Low relative to events defined by the Niño3.4 index (Fig. 9b). (We note the caveat that there is some uncertainty in comparing the magnitudes of the geopotential height responses between the composites of strong El Niño events as defined by ELI and Niño3.4, as the sample averages are computed over the area represented in the upper right hand corner of each plot. The average peak SWE date is shown by a vertical line for strong El Niño (red), strong La Niña (blue), and the climatology (black)

sizes in the composites are 3 and 12 events, respectively.) The differences in geopotential height responses due to ENSO definition highlight a pronounced deepening of the extratropical wave-train associated with an approximately $1600 \mathrm{~km}$ eastward shift in the center of tropical Pacific deep convection (from $175^{\circ} \mathrm{E}$ according to the Niño3.4 index to $189^{\circ} \mathrm{E}$ according to ELI for strong El Niño events; Fig. 10a). In addition, the anomalous anticyclones associated with El Niño are stronger when defined by ELI. Altogether, ELI captures a stronger El Niño-driven Rossby wave-train response, providing increased predictability of extremes associated with this tropical-extratropical teleconnection. On the other hand, the extratropical teleconnection during La Niña is weaker, asymmetric, and relatively insensitive to ENSO definition (Fig. 9c and d; Fig. 10b). Additionally, the extratropical response is weaker during La Niña compared to El Niño.

Together with this circulation response, ENSO can substantially modify moisture transport. Figure 11 shows composites of IVT anomalies for strong El Niño and La Niña events defined by ELI and the Niño3.4 index. Strong El Niño events show enhanced trans-Pacific IVT when defined by ELI (Fig. 11a) compared to the Niño3.4 index (Fig. 11b). In addition, the IVT extends further eastward toward the western US during strong El Niño events as defined by ELI compared with Niño3.4 (Fig. 10a) supporting the observed (Fig. 3) and simulated (Fig. 5) precipitation response to strong El Niño that is greater for ELI-based compared to 

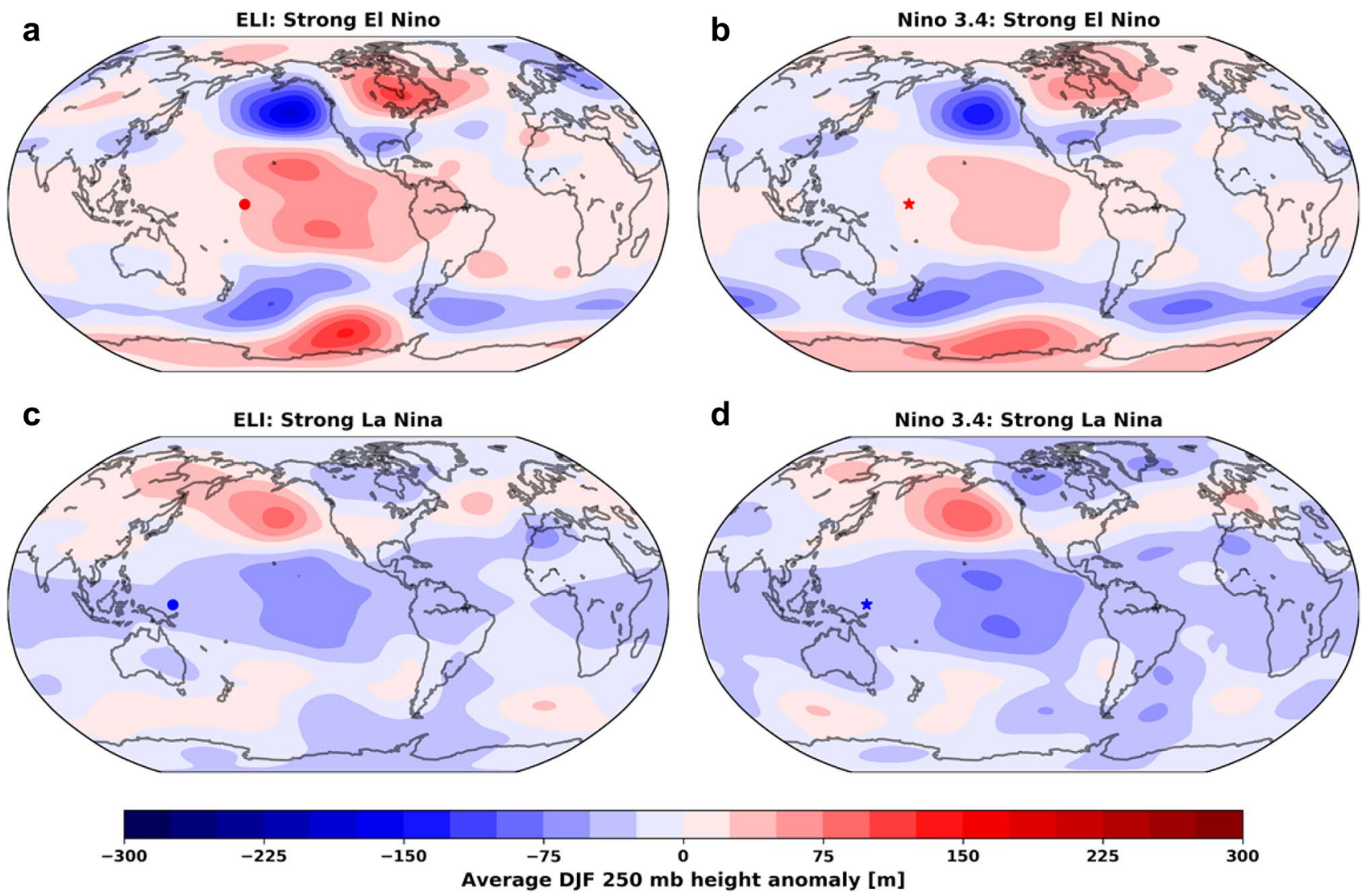

Fig. 9 Composites of DJF height anomalies (m) at 250-hPa relative to 1979-2010 climatology from the ERA-20C reanalysis for strong El Niño events as defined by $\mathbf{a}$ ELI and $\mathbf{b}$ the Niño3.4 index and strong La Niña events as defined by $\mathbf{c}$ ELI and $\mathbf{d}$ the Niño3.4 index. ENSO events are listed in Table 1. The dots/stars represent the DJF average ELI longitude as estimated by ELI for the years making up each composite
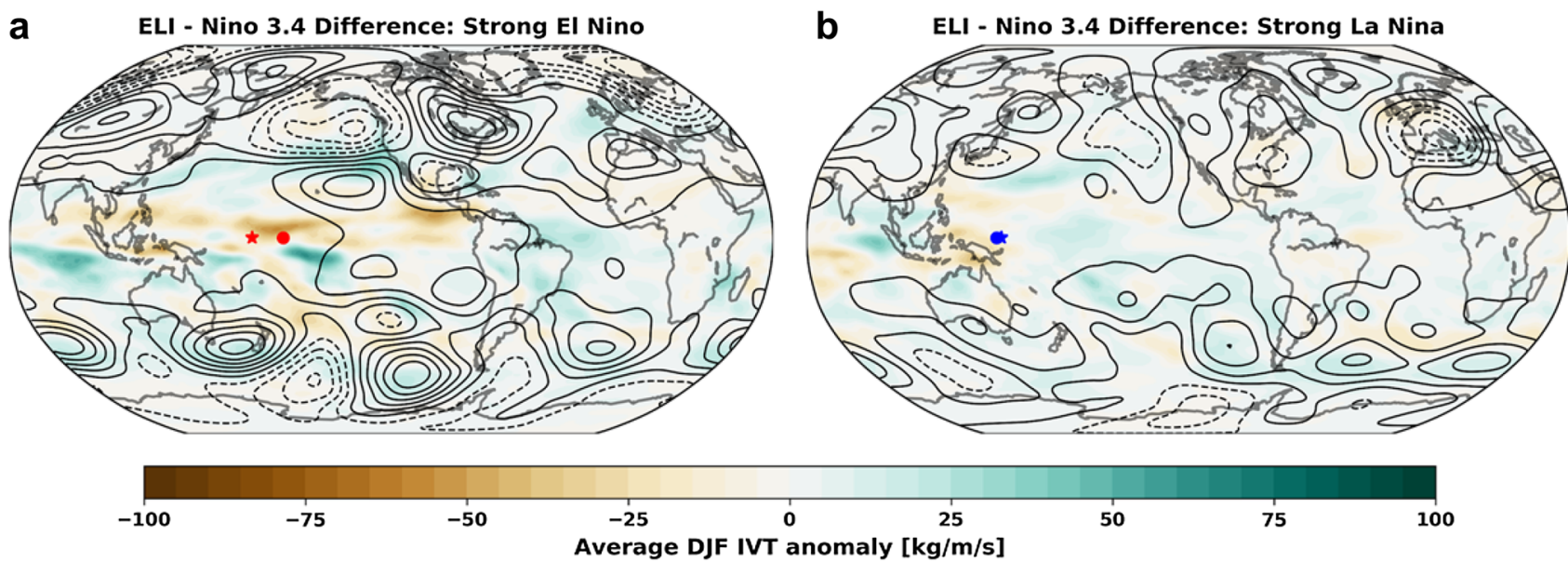

Fig. 10 The difference in DJF IVT (shaded; $\mathrm{kg} \mathrm{m}^{-1} \mathrm{~s}^{-1}$ ) and 250$\mathrm{hPa}$ geopotential height (contour; $\mathrm{m}$; solid denotes positive, dashed denotes negative) from the ERA-20C reanalysis for composites of a strong El Niño events and b strong La Niña events between ENSO events defined using ELI minus events defined using the Niño3.4 index. The dots and stars represent the average DJF ELI longitude according to events defined using ELI and the Niño3.4 index, respectively 

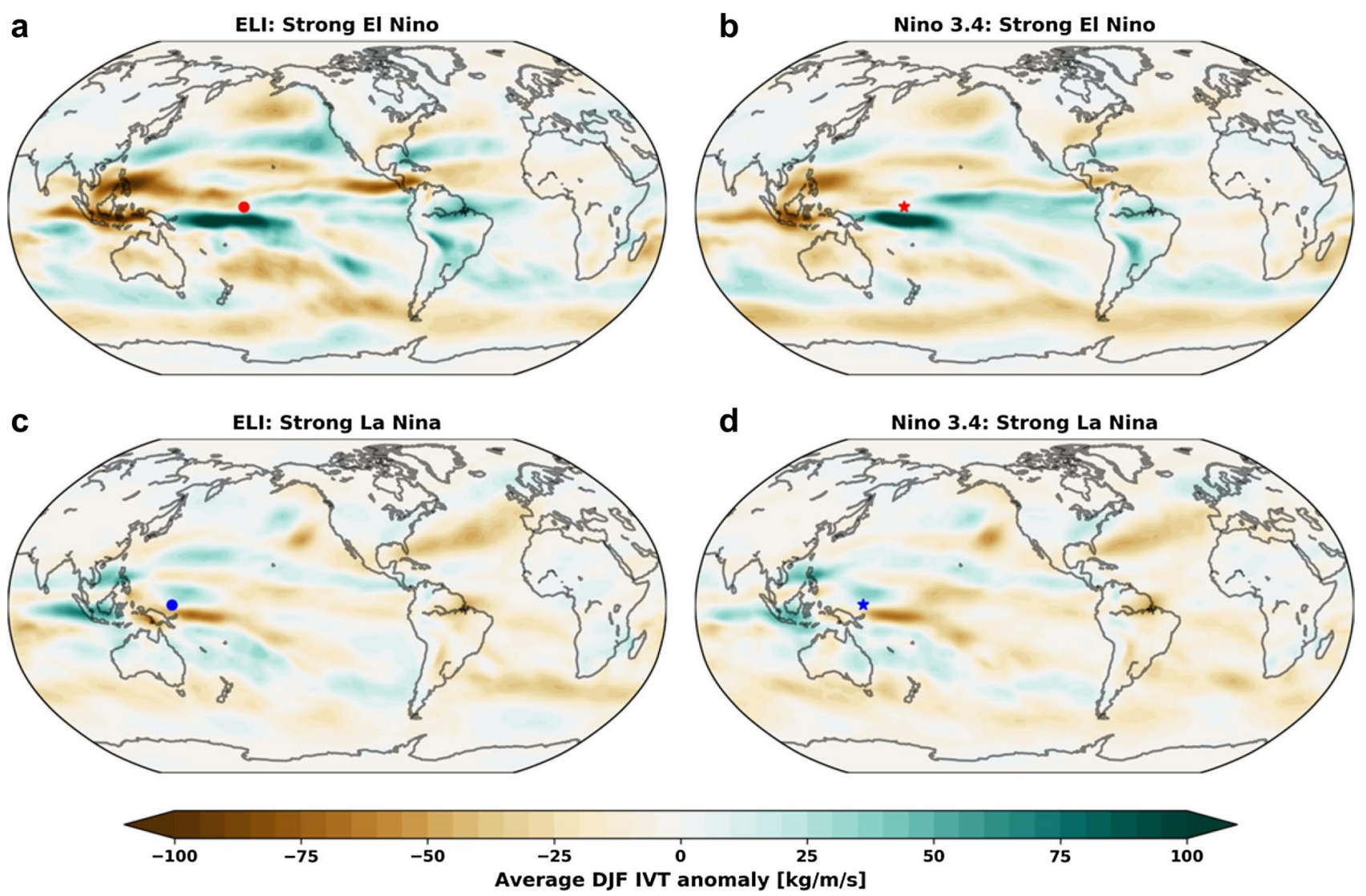

Fig. 11 Composites of DJF IVT anomalies $\left(\mathrm{kg} \mathrm{m}^{-1} \mathrm{~s}^{-1}\right)$ relative to 1979-2010 climatology from the ERA-20C reanalysis for strong El Niño events as defined by $\mathbf{a}$ ELI and $\mathbf{b}$ the Niño3.4 index and strong La Niña events as defined by $\mathbf{c}$ ELI and $\mathbf{d}$ the Niño3.4 index. ENSO

Niño3.4-based events. Similar to the upper-level geopotential height anomalies (Fig. 9c and d), the IVT response to strong La Niña events is similar regardless of ENSO definition (Fig. 11c and d).

There is a strong link between western US precipitation, IVT, and ARs, with ARs accounting for $~ 90 \%$ of the poleward moisture transport (Zhu and Newell 1998) and delivering 30-50\% of California's winter precipitation (Dettinger et al. 2011), specifically about $65 \%$ at the coast and $30 \%$ inland (Gershunov et al. 2017). Indeed, the increased IVT (Fig. 11a and b) and extratropical wave-train response (Fig. 9a and b) observed in the North Pacific during strong El Niño events is connected with an increase in AR frequency during individual strong El Niño events in MERRA-2 (Fig. 12a and b), consistent with analysis of observations and hindcast simulations (Kim et al. 2019; Zhou and Kim 2018). The sign of anomalies in winter AR activity over the western US (Fig. 12a-d) corresponds well with the observed western US precipitation patterns (Fig. 1b-e). We highlight that this good correspondence is present during extremely wet California winters driven by strong ELI-based El Niño events events are listed in Table 1. The dots/stars represent the DJF average ELI longitude as estimated by ELI for the years making up each composite

(i.e., 1982-1983 and 1997-1998), winters characterized by precipitation that is near-average over California and aboveaverage over the Pacific Northwest driven by moderate ELIbased El Niño events (i.e., 2015-2016), and extremely wet California winters driven by internal atmospheric variability (i.e., 2016-2017). This suggests that ARs contribute substantially to positive winter precipitation anomalies over the west coast regardless of the physical driver of the wet conditions, whether it be strong or moderate El Niño (i.e., an strong or moderate eastward shift in equatorial deep convection, respectively) or internal atmospheric variability. The WRF hindcasts (Fig. 12e-g) tend to capture the observed response in winter AR frequency well, regardless of whether the wet season was driven by strong or moderate El Niño or internal atmospheric variability, with the exception of a weakly negative simulated AR anomaly over California during 1997-1998. Despite this relatively poor regional AR representation during this specific season, the WRF hindcast reproduced the observed precipitation anomalies, suggesting that precipitation from other types of events, possibly 
a

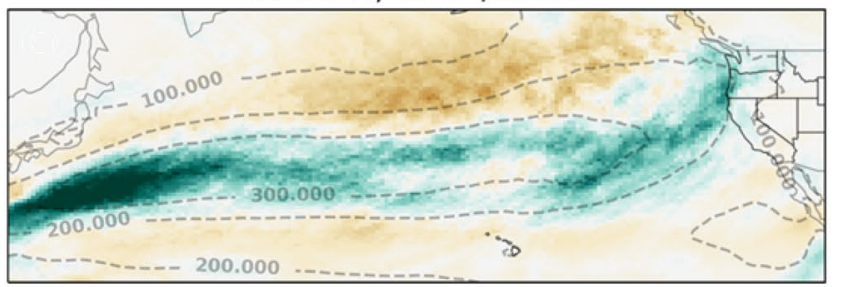

b
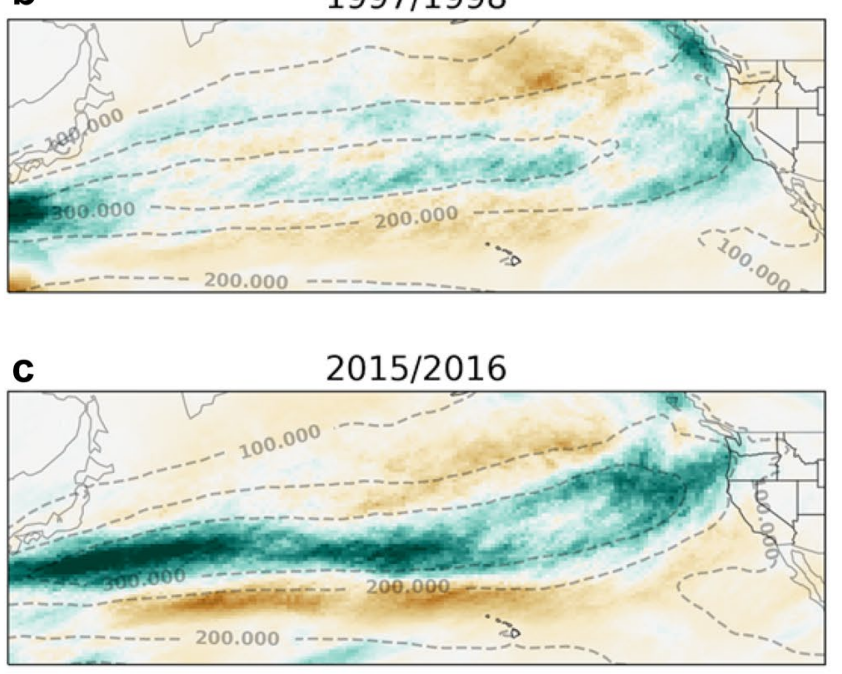

d

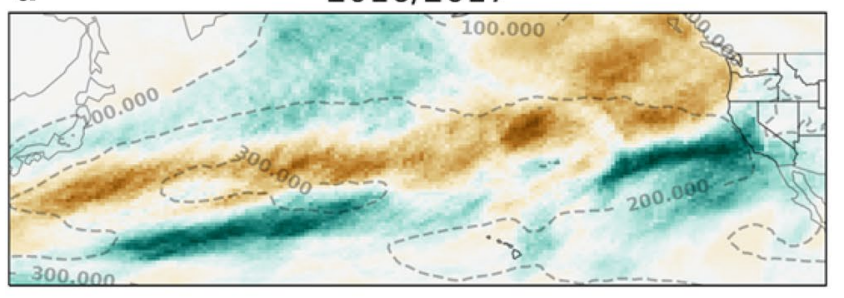

e

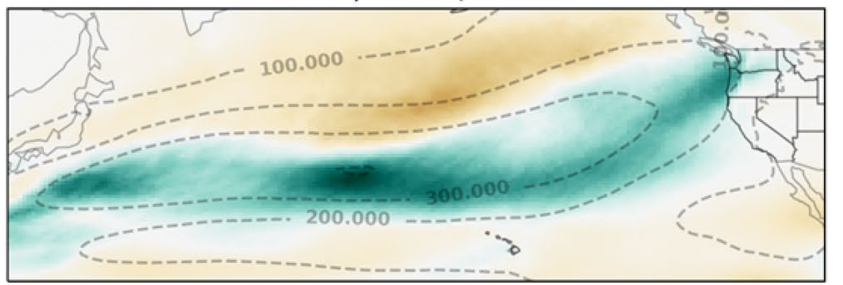

f

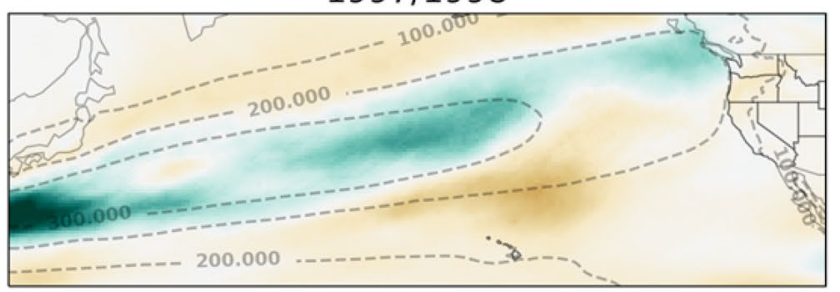

g

$2015 / 2016$

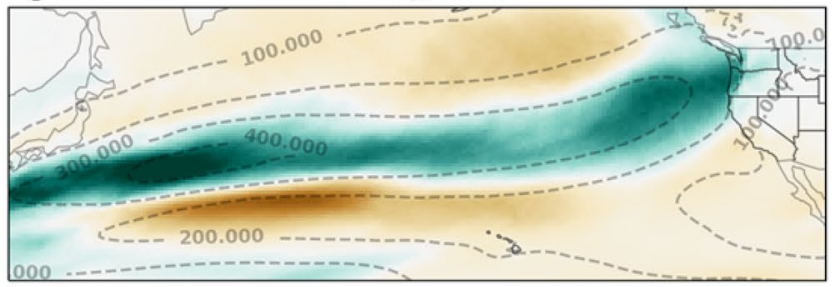

h

$2016 / 2017$

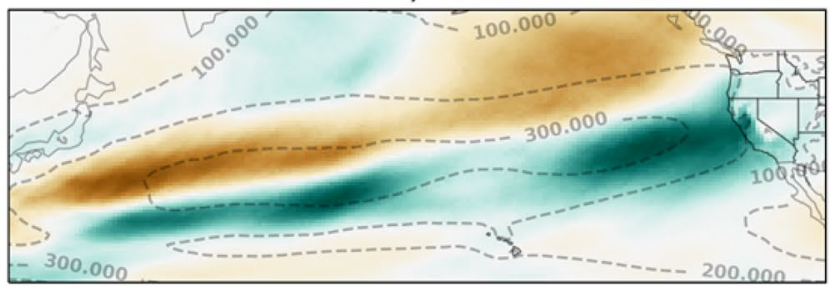

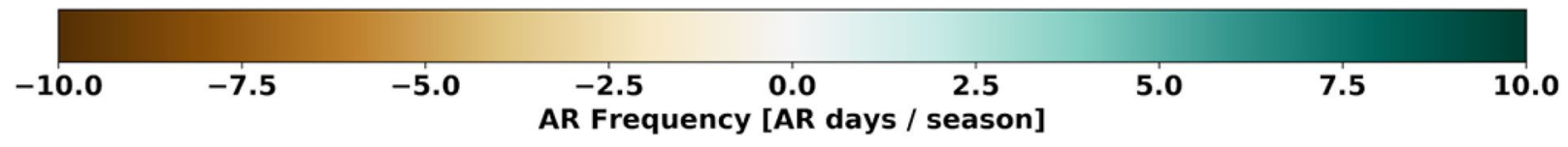

Fig. 12 Anomalies in AR activity (AR-days/season) during DJF of $\mathbf{a}$, e 1982-1983, b, f 1997-1998, c, g 2015-2016, and d, h 2016-2017 from MERRA-2 and the ensemble mean of the WRF simulations,

associated with mid-latitude cyclones, may be compensating for the weak AR activity.

\section{Conclusions}

ENSO can provide valuable predictability of daily to seasonal hydroclimate extremes in the western US, although recent estimates attribute only $6 \%$ of precipitation variability in California to ENSO (Savtchenko et al. 2015) and only with the DJF full-field IVT $\left(\mathrm{kg} \mathrm{m}^{-1} \mathrm{~s}^{-1}\right)$ shown in dashed contours, respectively. Anomalies are calculated relative to the 1981-2016 DJF climatology of the corresponding data source

$20 \%$ of variance in western US winter precipitation to SST forcing (Dong et al. 2018). However, by focusing on a specific source of predictability, namely strong El Niño events, and by considering their spatial variations, we found that we can improve the skill of ENSO as a predictor of western US hydroclimate variability (given a skillful ENSO forecast, typically after passing the spring predictability barrier (e.g. McPhaden 2003; Duan and Wei 2013; Lopez and Kirtman 2014; Ren et al. 2016)). An analysis of station and gridded 
observations together with large-ensembles of SST-forced regional and global climate model simulations reveals that:

- SST forcing was the main driver of the extremely wet seasons over California during the strong 1982-1983 and 1997-1998 ELI-based El Niño events and the near-average California precipitation during the moderate ELIbased/strong Niño3.4-based 2015-2016 El Niño event. In addition, winter precipitation over California is highly sensitive to the diversity of El Niño's spatial patterns. California did not experience an extremely wet winter during 2015-2016 due primarily to ocean warming that was located more towards the central Pacific compared to the 1982-1983 and 1997-1998 events, with little contribution from internal atmospheric variability. SSTAs in other tropical regions may also have played a role (Siler et al. 2017).

- By defining ENSO events using the ENSO Longitude Index (ELI; Williams and Patricola 2018), which uniquely captures the diversity and extremes of ENSO, we can extract more predictive value for California precipitation from strong El Niño events, compared to using the traditional Niño3.4 index, which measures SST anomalies in a fixed region and does not capture ENSO's diversity. Strong ELI-based El Niño events drive a substantial increase in the probability of extremely positive winter precipitation anomalies over the entirety of California, whereas strong La Niña events produce weaker regional drying.

- Internal atmospheric variability can also drive extremely wet winters in California, as was the case during 20162017. This is confirmed by comparing SST-forced global model simulations, which do not reproduce the observed western US precipitation anomalies during 2016-2017, with regional climate model simulations that are driven with observed SST and lateral boundary conditions, which do reproduce the observed precipitation patterns. Given the strong Madden-Julian Oscillation (MJO) activity near the Maritime Continent during early 2017, together with the documented links between MJO, western US precipitation, and the mid-latitude circulation (Zhou et al. 2012; Tseng et al. 2018), MJO may have contributed to California's extremely wet 2016-2017.

- Strong El Niño events lead to a significant increase in observed 10-year return values over the western US, with a signal that is substantially greater for ENSO events defined using ELI compared to Niño3.4, suggesting that ELI may provide better predictability for extreme daily precipitation.

- The way in which ENSO is defined results in major differences in the response of SWE to strong El Niño, including a change in sign over the Sierra Nevada and Cascades. In addition, SWE anomalies during strong
ELI-based El Niño years translate to considerable impacts on the water sector, particularly in California where a difference in peak SWE was equivalent to half of the total storage capacity of the state's largest reservoir, Lake Shasta.

- ELI can better describe El Niño-driven variability in western US precipitation primarily due to its ability to track the zonal shifts of equatorial Pacific deep convection, which is the source of anomalous atmospheric heating and resultant extratropical wave-train that drives anomalies in IVT and AR frequency. ARs contribute substantially to positive winter western US precipitation anomalies regardless of whether they are driven by strong or moderate El Niño or internal atmospheric variability.

This research indicates that (1) ENSO is a valuable source of winter hydroclimate predictability, especially during strong ELI-based El Niño events and (2) we can improve the value of ENSO as a hydroclimate predictor by considering the spatial diversity of ENSO events using the ENSO Longitude Index. ELI does not require the common practice of categorizing El Niño events (Ashok et al. 2007; Capotondi et al. 2015; Timmermann et al. 2018), and offers an effective yet simple way to improve ENSO as a source of subseasonal to seasonal hydroclimate predictability. In addition, it is important to note that although strong ELI-based El Niño events have a high probability of producing extremely wet conditions over California, ENSO is not the only driver of such seasons, which can also arise due to other SST variability and internal atmospheric variability (e.g. associated with MJO). Additional research on this topic, as well as on ENSO's relationship with the genesis location, intensity, and landfall location of ARs (Gershunov et al. 2017) and mid-latitude cyclones, and the implications for peak SWE and extreme streamflow events, is planned for the future. Finally, this research highlights that climate model representation and projection of ENSO extremes and diversity is a substantial source of uncertainty in future projections of western US hydroclimate (e.g., Guilyardi et al. 2009; Collins et al. 2010; Bellenger et al. 2014; Yeh et al. 2014; Taschetto et al. 2014; Wang et al. 2017b; Karamperidou et al. 2017; Chen et al. 2017), as models that project increases in strong El Niño and La Niña events (Williams and Patricola 2018) also produce increased seasonal precipitation extremes over California (Swain et al. 2018).

In summary, using a physically-based ENSO metric that fully captures ENSO diversity-in a single metric and for any climate state-better explains the teleconnected western US precipitation response compared to SSTA-based metrics. ELI addresses the challenges with SSTA-based metrics that each capture only a portion of the ENSO spectrum, by (1) eliminating the need to choose which SSTA-based metric to use to understand teleconnections to a particular region 
and (2) eliminating the uncertainty as to whether that SSTAbased metric will be informative in a changing climate. The broader implication of this research is that considering ENSO diversity from the physically-based, atmospheric perspective of ELI (Williams and Patricola 2018; Okumura 2019) provides a powerful capability for understanding the response of a variety of extreme events, including mid-latitude precipitation and tropical cyclones, to ENSO diversity in a changing climate.

Acknowledgements The authors thank two anonymous reviewers for their comments that have helped improve the manuscript. This material is based upon work supported by the U.S. Department of Energy, Office of Science, Office of Biological and Environmental Research, Climate and Environmental Sciences Division, Regional \& Global Climate Modeling Program, under Contract Number DE-AC0205CH11231 and under Award Number DE-SC0016605. This research used resources of the National Energy Research Scientific Computing Center (NERSC), a DOE Office of Science User Facility supported by the Office of Science of the U.S. Department of Energy under Contract No. DE-AC02-05CH11231. NCEP-II Reanalysis available at the Research Data Archive at the National Center for Atmospheric Research, Computational and Information Systems Laboratory, Boulder, CO. The MERRA-2 is available through the NASA Goddard Earth Sciences Data and Information Services Center. U.S. Climate Division precipitation data is from nClimDiv, is provided by NOAA/NCEI, Ashville, North Carolina, USA, and is available at https://www7.ncdc. noaa.gov/CDO/CDODivisionalSelect.jsp\#. CPC US Unified Precipitation data, GPCC Precipitation data, and GPCP data provided by the NOAA/OAR/ESRL PSD, Boulder, Colorado, USA, from their Web site at https://www.esrl.noaa.gov/psd/. ERA-20C reanalysis is provided by ECMWF, Reading, UK and is available at https://www.ecmwf.int/ en/forecasts/datasets/reanalysis-datasets/era-20c. Data from the C20C+D\&A simulations are available at http://portal.nersc.gov/c20c/. The CDWR station index data are available at https://cdec.water.ca.gov/ reportapp/javareports. The ENSO Longitude Index (ELI) is available at https://portal.nersc.gov/archive/home/projects/cascade/www/ELI.

Open Access This article is distributed under the terms of the Creative Commons Attribution 4.0 International License (http://creativeco mmons.org/licenses/by/4.0/), which permits unrestricted use, distribution, and reproduction in any medium, provided you give appropriate credit to the original author(s) and the source, provide a link to the Creative Commons license, and indicate if changes were made.

\section{References}

Adler RF et al (2018) The global precipitation climatology project (GPCP) monthly analysis (New Version 2.3) and a review of 2017 Global Precipitation. Atmosphere 9(4):138

Alexander MA, Bladé I, Newman M et al (2002) The atmospheric bridge: the influence of ENSO teleconnections on air-sea interaction over the global oceans. J Clim 15:2205-2231

Ashok K, Behera SK, Rao SA et al (2007) El Niño Modoki and its possible teleconnection. J Geophys Res 112:505

Bales RC, Molotch NP, Painter TH et al (2006) Mountain hydrology of the western United States. Water Resour Res 42:W08432. https ://doi.org/10.1029/2005WR004387

Bellenger H, Guilyardi E, Leloup J et al (2014) ENSO representation in climate models: from CMIP3 to CMIP5. Clim Dyn 42:1999-2018
Bjerknes J (1969) Atmospheric teleconnections from the equatorial Pacific. Mon Weather Rev 97:163-172

California Department of Food and Agriculture (CDFA) (2014) Agricultural Statistics Review, 2014-2015, 126 p. https://www.cdfa. ca.gov/statistics/PDFs/2015Report.pdf. Accessed 25 Sept 2016

California Department of Water Resources (CDWR) (2017) Water year 2017: what a difference a year makes. https://water.ca.gov/Legac yFiles/waterconditions/docs/2017/Water\%20Year\%202017.pdf. Accessed 3 Oct 2018

California Department of Water Resources (CDWR) (2019). https:// cdec.water.ca.gov/reportapp/javareports. Accessed 31 Mar 2019

Capotondi A, Wittenberg AT, Newman M et al (2015) Understanding ENSO diversity. Bull Am Meteorol Soc 96:921-938

Cash BA, Burls NJ (2019) Predictable and unpredictable aspects of US west coast rainfall and El Niño: understanding the 2015/16 event. J Clim 32:2843-2868

Cayan DR (1996) Interannual climate variability and snowpack in the western United States. J Clim 9:928-948

Cayan DR, Redmond KT, Riddle LG (1999) ENSO and hydrologic extremes in the western United States. J Clim 12:2881-2893

Chen M, Kumar A (2018) Winter 2015/16 atmospheric and precipitation anomalies over North America: El Niño response and the role of noise. Mon Weather Rev 146:909-927

Chen C, Cane MA, Wittenberg AT, Chen D (2017) ENSO in the CMIP5 simulations: life cycles, diversity, and responses to climate change. J Clim 30:775-801

Coles S (2001) An introduction to statistical modeling of extreme values. Springer, London

Collins M, An S-I, Cai W et al (2010) The impact of global warming on the tropical Pacific Ocean and El Niño. Nat Geosci 3:391

Dai A, Wigley TML (2000) Global patterns of ENSO-induced precipitation. Geophys Res Lett 27:1283-1286

DeFlorio MJ, Pierce DW, Cayan DR, Miller AJ (2013) Western US extreme precipitation events and their relation to ENSO and PDO in CCSM4. J Clim 26:4231-4243

Dennison PE, Brewer SC, Arnold JD, Moritz MA (2014) Large wildfire trends in the western United States, 1984-2011. Geophys Res Lett 41:2928-2933

Deser C, Simpson IR, McKinnon KA, Phillips AS (2017) The northern hemisphere extratropical atmospheric circulation response to ENSO: How well do we know it and how do we evaluate models accordingly? J Clim 30:5059-5082

Deser C, Simpson IR, Phillips AS, McKinnon KA (2018) How well do we know ENSO's climate impacts over North America, and how do we evaluate models accordingly? J Clim 31:4991-5014

Dettinger MD, Ralph FM, Das T et al (2011) Atmospheric rivers, floods and the water resources of California. Water 3:445-478

Dong L, Leung LR, Song F, Lu J (2018) Roles of SST versus internal atmospheric variability in winter extreme precipitation variability along the US west coast. J Clim 31:8039-8058

Duan W, Wei C (2013) The "spring predictability barrier" for ENSO predictions and its possible mechanism: results from a fully coupled model. Int J Climatol 33:1280-1292

Gelaro R, McCarty W, Suárez MJ et al (2017) The modern-era retrospective analysis for research and applications, version 2 (MERRA-2). J Clim 30:5419-5454

Gershunov A, Shulgina T, Ralph FM et al (2017) Assessing the climate-scale variability of atmospheric rivers affecting western North America. Geophys Res Lett 44:7900-7908

Guan B, Molotch NP, Waliser DE et al (2010) Extreme snowfall events linked to atmospheric rivers and surface air temperature via satellite measurements. Geophys Res Lett 37:L20401. https://doi. org/10.1029/2010GL044696

Guan B, Waliser DE, Ralph FM et al (2016) Hydrometeorological characteristics of rain-on-snow events associated with atmospheric rivers. Geophys Res Lett 43:2964-2973 
Guarín A, Taylor AH (2005) Drought triggered tree mortality in mixed conifer forests in Yosemite National Park, California, USA. For Ecol Manag 218:229-244

Guilyardi E, Wittenberg A, Fedorov A et al (2009) Understanding El Niño in ocean-atmosphere general circulation models: progress and challenges. Bull Am Meteorol Soc 90:325-340

Hagenstad M, Burakowski EA, Hill R (2018) Economic contributions of winter sports in a changing climate. Protect our winters, Boulder, CO, USA. Feb. 23, 2018. 71 pp. https://scholars.unh.edu/ cgi/viewcontent.cgi $?$ article $=1190 \&$ context $=$ ersc. Accessed 5 Mar 2019

Hanak E, Mount J, Chappelle C, Lund J, Medellín-Azuara J, Moyle P, Seavy N (2015) What if California's drought continues? Public Policy Institute of California Water Policy Center. pp 20. https ://www.ppic.org/publication/what-if-californias-drought-conti nues/. Accessed 15 Mar 2019

Harpold A, Dettinger M, Rajagopal S (2017) Defining snow drought and why it matters. Eos, Earth and Space Science News 98. https ://doi.org/10.1029/2017EO068775

Hecht CW, Cordeira JM (2017) Characterizing the influence of atmospheric river orientation and intensity on precipitation distributions over North Coastal California. Geophys Res Lett 44:9048-9058

Held IM, Lyons SW, Nigam S (1989) Transients and the extratropical response to El Nino. J Atmos Sci 46:163-174

Hoell A, Hoerling M, Eischeid J et al (2016) Does El Niño intensity matter for California precipitation? Geophys Res Lett 43:819-825

Hoerling MP, Kumar A (2002) Atmospheric response patterns associated with tropical forcing. J Clim 15:2184-2203

Hoerling MP, Kumar A, Zhong M (1997) El Niño, La Niña, and the nonlinearity of their teleconnections. J Clim 10:1769-1786

Horel JD, Wallace JM (1981) Planetary-scale atmospheric phenomena associated with the Southern Oscillation. Mon Weather Rev 109:813-829

Howitt R, Medellín-Azuara J, MacEwan D, Lund J, Sumner D (2014) Economic analysis of the 2014 drought for California agriculture, Tech. Rep. Center for Watershed Sciences, University of California, Davis, Davis, p 20

$\mathrm{Hu} \mathrm{H}$, Dominguez F, Wang Z et al (2017) Linking atmospheric river hydrological impacts on the US West Coast to Rossby wave breaking. J Clim 30:3381-3399

Huang X, Ullrich PA (2017) The changing character of twenty-firstcentury precipitation over the western United States in the variable-resolution CESM. J Clim 30:7555-7575

Huang B, Thorne PW, Banzon VF et al (2017) Extended reconstructed sea surface temperature, Version 5 (ERSSTv5): upgrades, validations, and intercomparisons. J Clim 30:8179-8205

Huffman GJ, Adler RF, Arkin P et al (1997) The global precipitation climatology project (GPCP) combined precipitation dataset. Bull Am Meteorol Soc 78:5-20

Jong B-T, Ting M, Seager R (2016) El Niño's impact on California precipitation: seasonality, regionality, and El Niño intensity. Environ Res Lett 11:054021

Kanamitsu M, Ebisuzaki W, Woollen J et al (2002) NCEP-DOE AMIPII reanalysis (R-2). Bull Am Meteorol Soc 83:1631-1644

Kapnick S, Hall A (2012) Causes of recent changes in western North American snowpack. Clim Dyn 38:1885-1899

Kapnick SB, Yang X, Vecchi GA et al (2018) Potential for western US seasonal snowpack prediction. Proc Natl Acad Sci U S A 115:1180-1185

Karamperidou C, Jin F-F, Conroy JL (2017) The importance of ENSO nonlinearities in tropical pacific response to external forcing. Clim Dyn 49:2695-2704

Kiladis G, Diaz HF (1989) Global climatic anomalies associated with extremes in the Southern Oscillation. J Clim 2:1069-1090
Kim H-M, Zhou Y, Alexander MA (2019) Changes in atmospheric rivers and moisture transport over the Northeast Pacific and western North America in response to ENSO diversity. Clim Dyn. https ://doi.org/10.1007/s00382-017-3598-9

Kumar A, Chen M (2017) What is the variability in US west coast winter precipitation during strong El Niño events? Clim Dyn 49:2789-2802

L'Heureux ML, Takahashi K, Watkins AB et al (2017) Observing and predicting the 2015/16 El Niño. Bull Am Meteorol Soc 98:1363-1382

Lee S-K, Lopez H, Chung E-S et al (2018) On the fragile relationship between El Niño and California rainfall. Geophys Res Lett 45:907-915

Lopez H, Kirtman BP (2014) WWBs, ENSO predictability, the spring barrier and extreme events. J Geophys Res D: Atmos 119:10-114

Maupin MA, Kenny JF, Hutson SS et al (2014) Estimated use of water in the United States in 2010. US Geological Survey Circular 1405, 56 p. https://doi.org/10.3133/cir1405

McPhaden MJ (2003) Tropical Pacific Ocean heat content variations and ENSO persistence barriers. Geophys Res Lett 30:2705

McPhaden MJ, Zebiak SE, Glantz MH (2006) ENSO as an integrating concept in earth science. Science 314:1740-1745

Menne MJ, Durre I, Korzeniewski B, McNeal S, Thomas K, Yin X, Anthony S, Ray R, Vose RS, Gleason B, Houston TG (2012a) Global historical climatology network-daily (GHCN-Daily), version 3. NOAA Natl Clim Data Cent. https://doi.org/10.7289/ v5d21vhz

Menne MJ, Durre I, Vose RS et al (2012b) An overview of the global historical climatology network-daily database. J Atmosp Ocean Technol 29:897-910

Mo KC, Higgins RW (1998) Tropical influences on California precipitation. J Clim 11(3):412-430

Mote PW, Hamlet AF, Clark MP, Lettenmaier DP (2005) Declining mountain snowpack in western North America. Bull Am Meteorol Soc 86:39-50

Mote PW, Li S, Lettenmaier DP et al (2018) Dramatic declines in snowpack in the western US. Npj Clim Atmosp Sci 1:2

Mundhenk BD, Barnes EA, Maloney ED (2016) All-season climatology and variability of atmospheric river frequencies over the North Pacific. J Clim 29:4885-4903

Musselman KN, Clark MP, Liu C et al (2017) Slower snowmelt in a warmer world. Nat Clim Change 7:214-219

Musselman KN, Lehner F, Ikeda K et al (2018) Projected increases and shifts in rain-on-snow flood risk over western North America. Nat Clim Change 8:808-812

O'Brien JP, O'Brien TA, Patricola CM, Wang S-Y (2019) Metrics for understanding large-scale controls of multivariate temperature and precipitation variability. Clim Dyn. https://doi.org/10.1007/ s00382-019-04749-6

Okumura YM (2019) ENSO diversity from an atmospheric perspective. Curr Clim Change Rep 5:245-257

Paek H, Yu J-Y, Qian C (2017) Why were the 2015/2016 and 1997/1998 extreme El Niños different? Geophys Res Lett 23:2885

Palmer PL (1988) The SCS snow survey water supply forecasting program: Current operations and future directions. In: Proceedings of Western Snow Conference, Kalispell, MT, pp 43-51

Payne AE, Magnusdottir G (2014) Dynamics of landfalling atmospheric rivers over the north pacific in 30 years of MERRA reanalysis. J Clim 27:7133-7150

Pierce DW, Cayan DR (2013) The uneven response of different snow measures to human-induced climate warming. J Clim 26:4148-4167

Pierce DW, Barnett TP, Hidalgo HG et al (2008) Attribution of declining western US snowpack to human effects. J Clim 21:6425-6444

Poli P, Hersbach H, Dee DP et al (2016) ERA-20C: An atmospheric reanalysis of the twentieth century. J Clim 29:4083-4097 
Quan X-W, Hoerling M, Smith L et al (2018) Extreme California rains during winter 2015/16: A change in El Niño teleconnection? Bull Am Meteorol Soc 99:S49-S53

Ralph FM, Martin Ralph F, Wilson AM et al (2019a) ARTMIP-early start comparison of atmospheric river detection tools: how many atmospheric rivers hit northern California's Russian River watershed? Clim Dyn 52:4973-4994

Ralph FM, Martin Ralph F, Rutz JJ et al (2019b) A scale to characterize the strength and impacts of atmospheric rivers. Bull Am Meteor Soc 100:269-289

Ren H-L, Jin F-F, Tian B, Scaife AA (2016) Distinct persistence barriers in two types of ENSO. Geophys Res Lett 43:10-973

Reynolds RW, Rayner NA, Smith TM, Stokes DC, Wang W (2002) An improved in situ and satellite SST analysis for climate. J Clim 15:1609-1625

Rhoades AM, Ullrich PA, Zarzycki CM (2018) Projecting 21st century snowpack trends in western USA mountains using variableresolution CESM. Clim Dyn 50:261-288

Risser MD, Stone DA, Paciorek CJ et al (2017) Quantifying the effect of interannual ocean variability on the attribution of extreme climate events to human influence. Clim Dyn 49:3051-3073

Risser MD, Paciorek CJ, Wehner MF et al (2019) A probabilistic gridded product for daily precipitation extremes over the United States. Clim Dyn. https://doi.org/10.1007/s00382-019-04636-0

Ropelewski CF, Halpert MS (1987) Global and regional scale precipitation patterns associated with the El Niño/Southern oscillation. Mon Weather Rev 115(8):1606-1626

Rutz JJ, Steenburgh WJ, Ralph FM (2014) Climatological characteristics of atmospheric rivers and their inland penetration over the western United States. Mon Weather Rev 142:905-921

Rutz J, Shields C, Lora J, Payne A, Guan B, Ullrich PA, O’Brien T, Leung R, Ralph F, Wehner M, Brands S, Collow A, Gershunov A, Goldenson N, Gorodetskaya I, Griffith H, Hagos S, Kashinath K, Kawzenuk B, Krishnan H, Lavers D, Magnusdottir G, Nguyen P, Prabhat, Ramos A, Sellars S, Tomé T, Walister D, Walton D, Wick G, Wilson A, Viale M (2019) The Atmospheric River Tracking Method Intercomparison Project (ARTMIP): quantifying uncertainties in atmospheric river climatology. J Geophys Res Atm (submitted)

Savtchenko AK, Huffman G, Vollmer B (2015) Assessment of precipitation anomalies in California using TRMM and MERRA data. J Geophys Res Atmos 120:8206-8215

Schneider U, Becker A, Finger P, Meyer-Christoffer A, Rudolf B, Ziese M (2016) GPCC full data reanalysis version 7.0: monthly landsurface precipitation from rain gauges built on GTS based and historic data. Research Data Archive at the National Center for Atmospheric Research, Computational and Information Systems Laboratory. https://doi.org/10.5065/D6000072

Schonher T, Nicholson SE (1989) The relationship between California rainfall and ENSO events. J Clim 2(11):1258-1269

Shields CA, Rutz JJ, Leung L-Y et al (2018) Atmospheric river tracking method intercomparison project (ARTMIP): project goals and experimental design. Geosci Model Dev 11:2455-2474

Siler N, Kosaka Y, Xie S-P, Li X (2017) Tropical ocean contributions to California's surprisingly dry El Niño of 2015/16. J Clim 30:10067-10079

Skamarock WC, Klemp JB (2008) A time-split nonhydrostatic atmospheric model for weather research and forecasting applications. J Comput Phys 227:3465-3485

Stone DA, Risser MD, Angélil OM et al (2018) A basis set for exploration of sensitivity to prescribed ocean conditions for estimating human contributions to extreme weather in CAM5.1-1 ${ }^{\circ}$. Weather Clim Extremes 19:10-19
Swain DL, Langenbrunner B, David Neelin J, Hall A (2018) Increasing precipitation volatility in twenty-first-century California. Nat Clim Change 8:427-433

Taschetto AS, Gupta AS, Jourdain NC et al (2014) Cold tongue and warm pool ENSO events in CMIP5: mean state and future projections. J Clim 27:2861-2885

Timmermann A, An S-I, Kug J-S et al (2018) El Niño-southern oscillation complexity. Nature 559:535-545

Tseng K-C, Barnes EA, Maloney ED (2018) Prediction of the Midlatitude Response to Strong Madden-Julian Oscillation Events on S2S Time Scales. Geophys Res Lett 45:463-470

Tziperman E, Cane MA, Zebiak SE et al (1998) Locking of El Nino's peak time to the end of the calendar year in the delayed oscillator picture of ENSO. J Clim 11:2191-2199

Ullrich PA, Zarzycki CM (2017) TempestExtremes: a framework for scale-insensitive pointwise feature tracking on unstructured grids. Geosci Model Dev 10:1069-1090

USGS (1998) El Niño 1997-1998: Damaging landslides in the San Francisco Bay Area. https://pubs.usgs.gov/fs/1998/0089/repor t.pdf. Accessed 3 Oct 2018

Vose RS, Applequist S, Squires M et al (2014) Improved historical temperature and precipitation time series for US Climate Divisions. J Appl Meteorol Climatol 53:1232-1251

Wang S, Anichowski A, Tippett MK, Sobel AH (2017a) Seasonal noise versus subseasonal signal: forecasts of California precipitation during the unusual winters of 2015-2016 and 2016-2017: S2S Forecast of CA precipitation. Geophys Res Lett 44:9513-9520

Wang C, Deser C, Yu J-Y et al (2017b) El Niño and southern oscillation (ENSO): a review. In: Glynn P, Manzello D, Enochs I (eds) Coral reefs of the eastern tropical pacific. Springer Science, pp 85-106

Westerling AL (2016) Increasing western US forest wildfire activity: sensitivity to changes in the timing of spring. Philos Trans R Soc B Biol Sci 371:20150178

White AB, Moore BJ, Gottas DJ, Neiman PJ (2019) Winter storm conditions leading to excessive runoff above California's Oroville dam during January and February 2017. Bull Am Meteor Soc 100:55-70

Williams IN, Patricola CM (2018) Diversity of ENSO events unified by convective threshold sea surface temperature: A nonlinear ENSO index. Geophys Res Lett 45:9236-9244

Yeh S-W, Kug J-S, An S-I (2014) Recent progress on two types of El Niño: observations, dynamics, and future changes. Asia-Pacific J Atmos Sci 50:69-81

Yeh S-W, Cai W, Min S-K et al (2018) ENSO atmospheric teleconnections and their response to greenhouse gas forcing. Rev Geophys $56: 185-206$

Zhang T, Hoerling MP, Wolter K et al (2018) Predictability and prediction of southern California rains during strong El Niño events: a focus on the failed 2016 winter rains. J Clim 31:555-574

Zhou Y, Kim H-M (2018) Prediction of atmospheric rivers over the North Pacific and its connection to ENSO in the North American multi-model ensemble (NMME). Clim Dyn 51:1623-1637

Zhou S, L'Heureux M, Weaver S, Kumar A (2012) A composite study of the MJO influence on the surface air temperature and precipitation over the Continental United States. Clim Dyn 38:1459-1471

Zhu Y, Newell RE (1998) A proposed algorithm for moisture fluxes from atmospheric rivers. Mon Weather Rev 126:725-735

Publisher's Note Springer Nature remains neutral with regard to jurisdictional claims in published maps and institutional affiliations. 